Functioning of the Default Mode Network with and without Methylphenidate Treatment in Patients with Attention Deficit Hyperactivity Disorder: A Systematic Review

by

\title{
Urusa Shah
}

A thesis submitted to the Faculty of Graduate and Postdoctoral Affairs in partial fulfillment of the requirements for the degree of

\author{
Master of Science \\ in \\ Neuroscience \\ Carleton University \\ Ottawa, Ontario \\ (C) 2020
}

Urusa Shah 


\begin{abstract}
Recent evidence has suggested that patients with ADHD display enhanced functioning of the Default Mode Network (DMN), resulting in altered functioning with its antagonistic Task Positive Network (TPN). To conduct this systematic review on DMN and TPN function and connectivity in ADHD patients using neuroimaging approaches, one investigator independently screened all titles, abstracts, and full-text articles and extracted data from selected studies that met the inclusion and exclusion criteria. After performing the search and screening methodology, 30 studies were detected that met the criteria for this systematic review. There were mixed findings of DMN connectivity with $45.45 \%$ finding reduced, $27.27 \%$ finding increased, and $27.27 \%$ of studies finding both increased and decreased connectivity in DMN regions. In addition, 50\% of studies found increased functional connectivity between the DMN and TPN, and majority of studies $(77.78 \%)$ found reduced anticorrelation between the DMN and TPN, in other words, a reduced DMN suppression. Overall it was found that DMN function is altered in patients with ADHD. Furthermore, all studies demonstrated that methylphenidate treatment results in a suppression of the DMN, suggesting a potential mechanism of action for its treatment of ADHD. Despite mixed findings regarding DMN intraconnectivity and interconnectivity with the TPN, this systematic review supports the conclusion that ADHD is a disorder of DMN dysfunction including dopamine alterations which can be reversed and treated by methylphenidate. This research will assist in the development of potential neuroimaging-based diagnostic approaches for ADHD as well as the tracking of treatment responses (Mak et al., 2017). Further research is needed to fully understand the correlation between DMN activity and ADHD.
\end{abstract}

Keywords: Attention Deficit Hyperactivity Disorder; Default Mode Network; Resting State Network; Task-Negative Network; Cognitive control networks, Task-Positive Network; Methylphenidate 


\section{Table of Contents}

Attention Deficit Hyperactivity Disorder.

.5

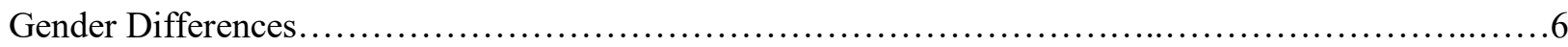

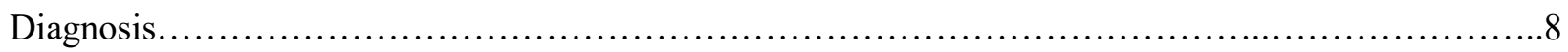

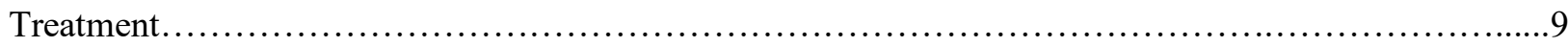

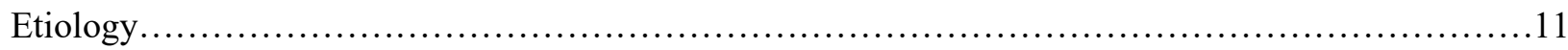

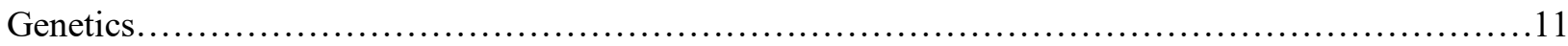

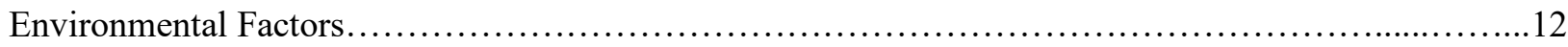

Structural and Functional Features of the ADHD Brain.......................................... 14

The Default Mode Network................................................................. 15

How is the Default Mode Network Studied?.................................................... 17

Development of the Default Mode Network................................................ 19

Default Mode and Task Positive Network....................................................20

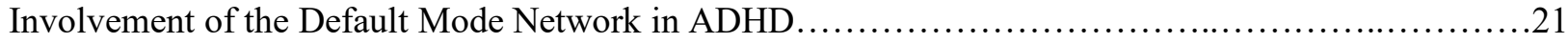

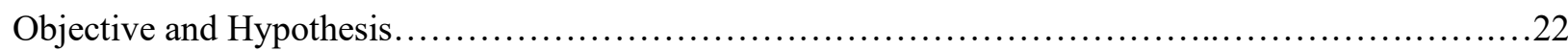

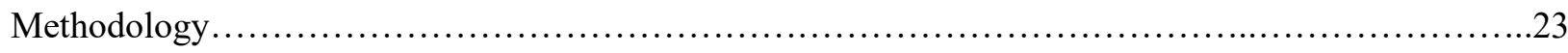

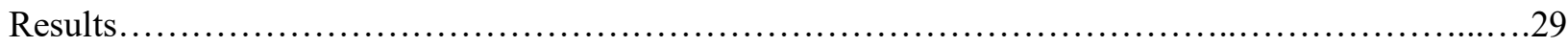

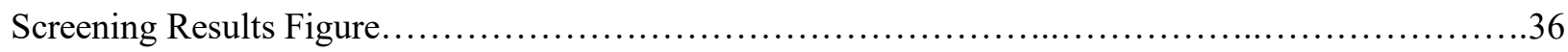

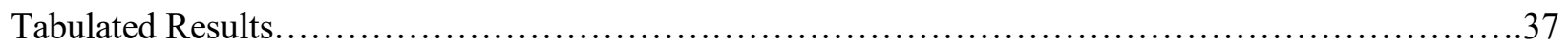

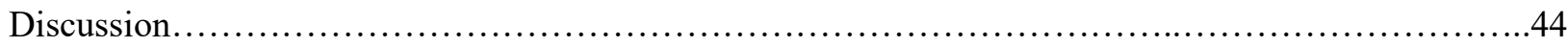




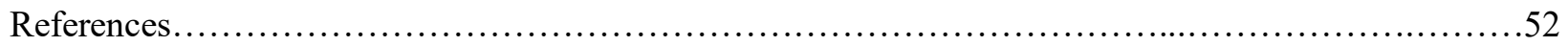

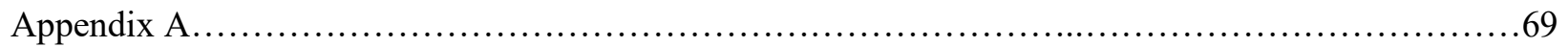




\section{Introduction}

\section{Attention Deficit Hyperactivity Disorder}

Attention Deficit Hyperactivity Disorder (ADHD) is a neuropsychiatric, developmental, and behavioural disorder (Saydam et al., 2015) characterized by symptoms of inattention, hyperactivity, and impulsivity (Belanger et al., 2018). It is a common, costly, and impairing syndrome (Nikolas \& Nigg, 2013) shown to be the third most common mental health disorder worldwide following depression and anxiety, and with an estimated 3.4\% of children and youth affected (Belanger et al., 2018). More specifically, an estimated worldwide prevalence of $7.2 \%$ is reported in children below the age of 18 years (Slobodin \& Davidovitch, 2019) and 2.5\% in adults (Hayman \& Fernandez, 2018). ADHD is shown to be most prevalent in high income countries in comparison to low income countries, with treatment seeking being low in all low, middle, and high-income countries (Fayyad et al., 2017).

The onset of ADHD takes place in childhood and pre-adolescence (Salvi et al., 2019), and although ADHD is considered to be a childhood and adolescence disorder, $50 \%$ of cases show a continuation of symptoms into adulthood (Belanger et al., 2018), resulting in significant executive and behavioural deficits and detrimental outcomes in various life domains (Rosello et al., 2020). This persistence of the disorder is influenced or predicted by enhanced symptom severity (both inattention and hyperactivity), high comorbidity with more than three mental disorders defined by the Diagnostic and Statistical Manual of Mental Disorders (DSM), parental anxiety, and parental antisocial personality disorder (Belanger et al., 2018).

ADHD in adults is highly comorbid with DSM-IV/Composite International Diagnostic Interview based anxiety, mood, behavior, and substance use disorders with treatment seeking 
associated with these comorbid conditions rather than ADHD itself (Fayyad et al., 2017). The clinical symptoms most significantly displayed in adulthood include struggles with planning/organizing everyday activities, extreme restlessness, and damaging impulsivity which result in difficulties to keep a job and relationships (Salvi et al., 2019). Furthermore, individuals with ADHD experience functional impairments in academics, display various risky behaviors, are involved in financial problems with a dependence on public aid, and are at risk of poverty (Rosello et al., 2020).

The three major symptoms of ADHD can be expressed individually or in a combination (Krain \& Castellanos, 2006) resulting in subtypes of ADHD; ADHD with predominantly symptoms of inattention (ADHD-I), ADHD with predominantly hyperactivity and impulsivity symptoms (ADHD-H), and lastly ADHD displaying a combination of all symptoms (ADHD-C) (Saydam et al., 2015). As seen, individuals with ADHD are a heterogeneous group as they display high levels of variability in the frequency and extent of symptoms, along with the resulting impairments from these symptoms (Adesman, 2001). In terms of prevalence of the subtypes, Salvi et al (2019) found that $18.3 \%$ were those of the inattentive subtype, $8.3 \%$ hyperactive/impulsive subtype and 70\% combined subtype. This classification system which includes the subtypes of ADHD may result in a more accurate diagnosis of the disorder.

\section{Gender Differences}

ADHD is more commonly diagnosed and treated in males compared to females with a male-tofemale ratio of $3: 1$ in population-based studies and between 5:1 to 9:1 in clinical samples (Skogli-et al., 2013). However, the 3:1 ratio in children narrows significantly in adults, ranging from 1:1 to 2:1 (Hayman \& Fernandez, 2018). 
The overall diagnostic criteria of ADHD for each of the DSM-IV subtypes is more likely to be met by boys, with a higher proportion of females having ADHD-I, and a higher proportion of males having ADHD-C (Willcutt, 2012). In addition, in non-referred males and females with ADHD, Biederman et al. (2005) found that there was a difference in DSM-IV subtypes, psychiatric comorbidity, or treatment history, while showing similar cognitive, psychosocial, school, and family functioning. This difference may be due to differences in the expression of symptomology. Females with ADHD have shown to have less hyperactive and impulsive symptoms while having higher inattentive symptoms in comparison to males with ADHD, hence females with ADHD are more commonly of the inattentive subtype (Skogli et al., 2013). Some research however has found no gender differences in impulsivity, academic performance, social functioning, fine motor skills, parental education or parental depression, though females with ADHD have shown more intellectual impairment with decreased levels of hyperactivity and externalizing behaviours compared to males with ADHD (Gaub \& Carlson, 1997). In addition, females have shown to have higher rates of self-reported anxiety symptoms (Skogli et al., 2013). Reduced disruptive behaviours in females with ADHD may cause a referral bias resulting in less likelihood in identification of symptoms and less treatment options for females with ADHD (Skogli et al., 2013).

Research findings that demonstrate that boys have a higher chance of being diagnosed and treated for symptoms related to ADHD in comparison to females may be due to research having a higher proportion of subjects being boys, and also due to previous research focusing on subjective factors of ADHD which greatly contribute to reporter's bias (Slobodin \& Davidovitch, 2019). Slobodin \& Davidovitch (2019) carried out a study to address some of these limitations and found that girls have higher inattention problems than boys, with no differences in levels of 
hyperactivity and impulsivity, based on reports of parents and teachers. However, according to a continuous performance task (CPT), it was shown that boys had a higher level of impulsivity. In addition, there was no difference in levels of distractibility during the CPT performance with there being no difference based on type of distractor. These results illustrate that the effects of gender on ADHD symptoms can differ between subjective and objective measures (Slobodin \& Davidovitch, 2019).

\section{Diagnosis}

Diagnosis of ADHD is quite challenging due to a lack of specific biomarkers, symptom specificity as well as there being a large scope of differential diagnosis and comorbidities present with the disorder (Belanger et al., 2018). There is no individual test for the diagnosis of ADHD however, just like other medical and psychiatric conditions, clinical diagnosis is established by assessing symptomatology and the associated impairments (Adesman, 2001).

Diagnosis of ADHD is based on the DSM with a large progression in the diagnosis throughout the five editions (Epstein \& Loren, 2013). In the DSM-II, the disorder was known as a Hyperkinetic Reaction of Childhood, which suggests that diagnosis mainly targeted the symptoms associated with excessive motor activity (Epstein \& Loren, 2013). In the DSM-III, which came about in 1980, the focus of diagnostic symptoms changed to attention, impulsivity and hyperactivity with a change in the name of the disorder to Attention Deficit Disorder (ADD), with or without the symptoms of hyperactivity (Epstein \& Loren, 2013). This term was later changed to Attention Deficit/Hyperactivity Disorder (ADHD) in the DSM-III-R, eliminating ADD without hyperactivity (Epstein \& Loren, 2013). In DSM-IV the three subtypes of ADHD were presented with the most current $D S M$, the $D S M-\mathrm{V}$, consisting of 5 criterions (A-E); ADHD 
symptoms, age of onset, pervasiveness, impairment and exclusionary symptoms (Epstein \& Loren, 2013).

Although there have been changes that were made between the DSM-IV and V, similar screening tools may be applied to gather diagnostic information, with the symptoms having to be present in various settings and should result in an impairment in everyday functions (Belanger et al., 2018). Specifically, for ADHD-C, minimum six out of nine symptoms involving inattention and/or hyperactivity/impulsivity must be met, with the impairment induced by the symptoms being present in two or more locations (i.e. home and school) along with a significant impairment in social, school or work functioning (Singh, Yeh, Verma \& Das, 2015). In regards to the other two subtypes of ADHD, diagnosis for ADHD-I requires the child to only meet the inattention criteria and the diagnosis for ADHD-H requires the child to only meet the hyperactive-impulsive criteria (Singh et al., 2015).

\section{Treatment}

ADHD is commonly treated by prescribing medications such as psychostimulants, the major ones being methylphenidate, amphetamine, and pemoline (Singh et al., 2015). Pharmacological, genetic, imaging and animal model research has pointed towards dopamine dysregulation to be a major factor in the pathology of the disorder (Curatolo et al., 2010). Dopamine is a neurotransmitter that is created in the substantia nigra, ventral tegmental area, and hypothalamus of the brain, and is responsible for reward and movement regulation (Olguin et al., 2016). Therefore, ADHD can be treated by modulating the dopaminergic system with stimulants (Grimm et al., 2018), with methylphenidate being the most prescribed stimulant medication (Sharma \& Couture, 2014). Since this pharmaceutical functions to inhibit the dopamine 
transporter (DAT) resulting in elevated levels of dopamine, the dopamine hypothesis has been proposed dopamine depletion being a potential pathology behind ADHD (Genro et al., 2010). There is also a non-stimulant pharmaceutical known as atomoxetine which was developed in 2002 to treat ADHD (Childress, 2016). Although not as effective as stimulants, it has shown to overall improve quality of life, emotional liability, and major ADHD symptoms (Childress, 2016).

Psychosocial interventions are also a very good option for treatment which may include a combination with pharmacotherapy (Adesman, 2001). There are additional nonpharmacological interventions that may be implemented to treat ADHD. An example of such an intervention is neurostimulation which involves the stimulation of brain regions expressing abnormal brain activity in ADHD (Wong \& Zaman, 2019). Transcranial Direct Current Stimulation (tDCS) is a form of non-invasive brain stimulation enabling the modulation of brain activity (Hoy et al., 2013). It encompasses an application of a weak electrical current by two electrodes - anode and a cathode, that are placed on the scalp allowing a change in cortical excitability (Hoy et al., 2013; Nitsche et al., 2008). Another treatment that may be effective in treatment of ADHD is neurofeedback. Neurofeedback measures one's brain activity which is pre-processed and is visible to the participant (Enriquez-Geppert et al., 2019). This feedback allows the participant to learn to self-regulate his or her own brain activity which directly modifies the underlying neural activity associated with cognition and behaviour (EnriquezGeppert et al., 2019). These alternative forms of treatments may be effective in treating ADHD symptoms without the adverse side effects of medications. 


\section{Etiology}

There are multiple causes associated with the onset of ADHD including a combination of genetic, neurological, and environmental factors (Belanger et al., 2018). Overall, ADHD is thought to be caused by an interaction in genes and the environment, with the children who are predisposed to ADHD due to a genetic basis expressing the condition when present in a correct environment, usually one involving chaotic parenting (Singh et al., 2015).

\section{Genetics}

A large body of research has demonstrated that genetics plays an important role in the etiology of ADHD and the comorbidity with other disorders (Faraone \& Larsson, 2018). Though ADHD is a highly heritable mental disorder, it may also be acquired with some individuals having both a genetic and acquired basis of ADHD (Voeller, 2004).

Family and twin studies have demonstrated ADHD to be $70-80 \%$ hereditary (Franke et al., 2012). Siblings of those diagnosed with ADHD are at a higher risk of developing ADHD compared to siblings of healthy controls (Faraone \& Larsson, 2018). More specifically, first degree relatives of ADHD patients have an increased risk of developing ADHD compared to controls, and siblings of those with ADHD have a two to three times the risk of having ADHD compared to siblings of controls (Adesman, 2001). In addition, there is a high risk of $57 \%$ for the offspring of adults with ADHD to develop ADHD (Franke et al., 2012), with approximately $25 \%$ of children with ADHD having parents that meet the diagnostic criteria of ADHD (Voeller, 2004). 
Coming down to the cellular level, gene variants determine the risk for developing ADHD and are critical for development of the brain (Belanger et al., 2018). Since ADHD can be treated by modulating the dopaminergic system with stimulants, much research has focused on studying dopaminergic receptors (DRD4, DRD5) and transporters (DAT1) (Grimm et al., 2018). Genes of the dopaminergic and serotonergic system have been extensively studied and are implicated in the susceptibility of ADHD (Zhang et al., 2012). Some candidate genes like DAT1, DRD4, DRD5, 5HTT, HTR1B are found to be positively linked with childhood ADHD (Grimm et al., 2018). Genes encoding for Synaptosomol-associated protein of 25kD (SNAP 25), which is a protein that modulates neurotransmitter release, as well as Catechol-OMethyltransferase (COMT), which is an enzyme responsible for the breaking down of dopamine, adrenaline and noradrenaline, is implicated in ADHD as well (Thaper \& Stergiakouli, 2008). There are additional candidate genes encoding Brain Derived Neurotrophic Factor (BDNF), Cadherin-13 (CDH13), Nitric Oxide Synthase (NOS1), serotonin transporter SLC6A4, among multiple others that have been implicated in ADHD (Grimm et al., 2018). This research illustrates a significant link between genetics and ADHD, with the inattentive and hyperactive or impulsive types differing in heritability (Voeller, 2004).

\section{Environmental Factors}

Although genetics plays a major role in the development of ADHD, there are also environmental factors that come into play such as prenatal substance exposures, heavy metal and chemical exposure, nutritional factors, and lifestyle/psychosocial factors (Froehlich et al., 2011), which ultimately alter gene function through epigenetic mechanisms (Thaper et al., 2012). Low 
birth weight, maternal smoking, alcohol and drug use, and stress/anxiety in pregnancy are also factors that contribute to the development of ADHD (Thaper et al., 2012).

Organic pollutants and lead specifically can impair cognitive and neural systems which are known to be implicated in ADHD (Thaper et al., 2012). There has been significant evidence showing the relationship between lead exposure and at least one type of ADHD (Daneshparvar et al., 2016). Braun et al. (2006) found that an exposure to prenatal tobacco and environmental lead are risk factors for the development of ADHD in US children. Lead is a neurotoxin that produces abnormal behaviors by affecting neurotransmitters and permanently altering glucocorticoid regulation via the hypothalamic-pituitary axis (HPA) (Daneshparvar et al., 2016). Glucocorticoid hormones are effector hormones of the HPA axis, a neuroendocrine system with a major role in stress regulation (Spencer \& Deak, 2017). In addition, lead produces changes in dopaminergic and gamma-aminobutyric acid-ergic (GABA) systems (Daneshparvar et al., 2016), with GABA playing an important role in the inhibition of activity in the brain and spinal cord when needed (Jewett \& Sharma, 2020).

Furthermore, some additional environmental factors that are associated with neurobehavioral effects of ADHD are copper, iron and omega-3 fatty acid deficiency, electronic media exposure, folate deficiency during pregnancy, exposure to food additives, manganese, and mercury (Froehlich et al., 2012). As we see, the environmental effects are also a major component in the development in ADHD. 


\section{Structural and Functional Features of the ADHD Brain}

Several Magnetic Resonance Imaging (MRI) studies have found abnormal and/or reduced volumes of specific brain regions in persons with ADHD in comparison to normal subjects (Adesman, 2001). These brain regions include the caudate nucleus and globus pallidus, critical for motor activity, frontal lobes which are critical for attention, and some regions of the corpus collosum, with these regions being approximately $10 \%$ smaller in patients with ADHD compared to controls (Adesman, 2001). In addition, there is a relative reduction in the size of the cerebellum which also plays a critical role in executive functioning due to it having numerous connections with the prefrontal cortices (Voeller, 2004). Neuroimaging research has also shown a reduction in brain volume and neural activities in the basal ganglia and limbic system in those with ADHD (Hayashi \& Iwanami, 2018).

To further these findings, a study conducted by Qiu et al. (2011) found a focal thinning of the bilateral frontal brain regions and the right cingulate cortex. Additionally, the cortex has been shown to be significantly thinner in in the dorsal attention network and limbic regions (Proal et al., 2011). Interestingly, individuals with remitting ADHD display a thicker cortex in the medial occipital cortex, insula, parahippocampus, and prefrontal regions, compared to those with persistent ADHD (Proal et al., 2011). Furthermore, those with ADHD show an altered maturing or development of white matter fiber bundles as well as gray matter density in the middle and superior temporal gyrus and fronto-basal regions of the frontal lobes, illustrated by structural shape changes (Gehricke et al., 2017). Overall patients with ADHD have demonstrated a reduced total cerebral volume compared to controls (Voeller, 2004). 
In addition to a difference in structural development, there are also distinctions in functional activity in the prefrontal cortex, basal ganglia, anterior cingulate cortex and the cerebellum (Belanger et al., 2018). In terms of brain function, functional brain studies have revealed a dysfunction of the default mode network (DMN) in ADHD (Hayashi \& Iwanami, 2018) suggesting that ADHD can be regarded as a DMN disorder (Kaboodvand et al., 2020)

\section{The Default Mode Network}

When the brain is at rest and is not involved in goal-directed activities, there is still activity within the brain (Mak et al., 2017). Research has continually found enhancement in regional brain activity during goal-directed behaviors, however, there have also been findings that demonstrate task-induced reductions in regional brain activity even when the control state is lying quietly with eyes closed or passively observing a stimulus (Raichle et al., 2001). The increases in brain activity have been task specific, however, the reductions in brain activity seem to be task independent, with a very slight variation across a wide range of tasks (Raichle et al., 2001). This suggests the presence of a baseline default mode of brain function which is switched off during goal-directed behaviors (Raichle et al., 2001). This led to the discovery of a neural network in the brain known as the Default Mode Network (DMN), which displays elevated levels of functional activity during the resting state, hence is known as a Resting State Network (RSN) (Watabe \& Hatazawa, 2019). The brain activity within the DMN is depicted by very low neuronal oscillations which allows temporal synchronization amongst the associated brain regions (Broyd et al., 2009). It is also viewed as a task-negative network as it displays a deactivation with an increased demand for an externally focused task (Smith et al., 2019). The extent of deactivation of the DMN is correlated with difficulty or demand level of the task 
(Broyd et al., 2009) with an increased deactivation associated with memory retrieval difficulty (Smith et al., 2019). These task-deactivated brain regions consume greater amounts of glucose while in a resting state since they are more active during rest (Hasson et al., 2009).

The DMN consists of roughly three sections: the ventral medial prefrontal cortex, the dorsal medial prefrontal cortex, and the lateral parietal cortex (Raichle, 2015). More specifically, it consists of the posterior cingulate cortex which sits next to the precuneus, the entorhinal cortex (Raichle, 2015), medial temporal lobe, temporoparietal junction (Bulgarelli et al., 2020), retrospenial cortex/posterior cingulate, inferior parietal lobe, lateral temporal cortex, hippocampal formation (Buckner et al., 2008), and the anterior cingulate cortex (Washington \& VanMeter, 2015) forming a large and complex neural network.

Default mode network
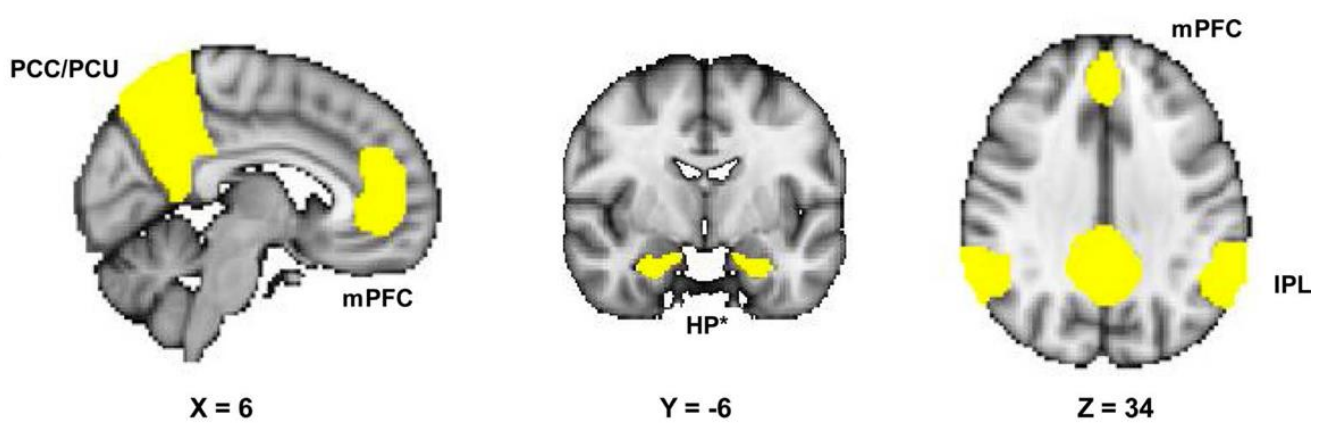

Figure 1: The Default Mode Network (van Oort et al., 2017)

PCC: Posterior Cingulate Cortex; PCU: Precuneus; mPFC: Medial Prefrontal Cortex; HP: Hippocampus; IPL: Inferior Parietal Lobe

The DMN is known as an "intrinsic system" that is involved in self-referential mental processing (Bulgarelli et al., 2019), with the functional connectivity being positively correlated with cognitive processes (Mak et al., 2017). It is implicated in functions such as mindwandering, daydreaming, and reflecting on oneself and one's life (Alexandar \& Farelly, 2018). It 
plays an important role in cognitive processes such as memory, thinking, and the integration of social information (Watabe \& Hatazawa, 2019). It is also involved in autobiographical memory, theory of mind and mentalizing, planning and envisioning the future (Bulgarelli et al., 2019), and internally generated cognition like again mind wandering, but also rumination (Norman et al., 2017). This is confirmed by neuroimaging research in which they found that DMN activity at rest is positively correlated with mind wandering and self-thoughts (Bulgarelli et al., 2019). A similar finding is reported by Son et al. (2019) in which the results indicated an increased connectivity of the DMN during mind wandering. Furthermore, DMN regions have elevated levels of activity with increased self-relevance and self-projection (Smith et al., 2019). However, this is not the case for rule retrieval which may be due to rules not having a deeply personal component, and don't require remembering the past (Smith et al., 2019). Therefore, this suggests that the role of the DMN in memory retrieval does not stretch to remembering self-irrelevant information such as task rules (Smith et al., 2019).

The DMN also plays a role in social cognition and integration of cognitive processes with different areas of the DMN being involved in different functions such as the PCC being linked to autobiographical memory and frontal areas being linked to self-reference (Heine et al., 2012). This demonstrates that resting state activity can to a certain extent provide information about cognitive function (Heine et al., 2012).

\section{How is the Default Mode Network Studied?}

Magnetic Resonance Imaging has drastically helped researchers correlate neurocognitive functions with changes in brain structure and activity at a group level (Baroni \& Castellenos, 2015). Functional neuroimaging involves various techniques such as Positron Emission 
Tomographic (PET) scans, Functional Magnetic Resonance Imaging (fMRI), Single Photon Emission Computerized Tomography (SPECT), and Magnetic Resonance Spectroscopy (MRS) (Voeller, 2004). The PET scan measures brain activity based on blood flow which is associated with oxygen usage (Raichle, 2015). Specifically, an enhancement in brain activity above a resting state involves increased blood flow with the increase being more than the oxygen consumed (Raichle, 2015). Therefore, oxygen increases as the ratio of oxygen consumed to oxygen delivered, known as the oxygen extraction fraction (OEF), is decreased (Raichle, 2015). The fMRI is also a very useful method to study brain activity. It is sensitive to the amount of oxygen carried in the blood which allows it to pick up on the alterations in oxygen content within the blood upon increased brain activity (Raichle et al., 2001). This is detected by a signal known as the blood oxygen level-dependent (BOLD) (Raichle et al., 2001), allowing examination of underlying neural architecture (Hayashi, 2011). BOLD fMRI especially is a valuable technique for analyzing the pathology of ADHD (Qiu et al., 2011).

Examining brain networks based on self-organized patterns is known as resting-state fMRI (Hayashi, 2011), in which the BOLD signals are analyzed without a particular experimental task or input present (Smitha et al., 2017) . This resting-state recording therefore measures the intrinsic activity of the brain during quiet wakefulness, without any cognitive, sensory or social stimulation (Bulgarelli et al., 2020). During such experiments, participants are directed to rest quietly in the fMRI with their eyes closed (Lee et al., 2012). In examples of studies that utilized resting-state fMRI, participants were directed to rest quietly without performing any cognitive, motor, or language tasks while their resting state brain activity was measured (Lee et al., 2012; Biswal et al., 1995). A major variable that is used to measure activity of the DMN is the degree of functional connectivity which is defined as the patterns of 
synchronized neuronal activity in anatomically separate brain regions (Gracia-Tabuenca et al., 2020).

Although the fMRI delivers high spatial resolution for measuring brain function, it doesn't deliver a very good temporal resolution (Broyd et al., 2009). A neuroimaging technique that provides excellent temporal resolution is known as electroencephalography (Broyd et al., 2009). These neuroimaging techniques has allowed researchers to investigate the role of the DMN in neurological and psychiatric disorders.

\section{Development of the Default Mode Network}

Overall, the DMN is sparsely connected and becomes a more integrated system with stronger connections in adulthood (Konrad \& Eickhoff, 2010). More specifically, at two weeks we see a primitive and incomplete DMN following a rise in the number of brain areas displaying connectivity along with a rise in the percent of connections at an age of one year (Gao et al., 2009). The DMN has shown to have a maximum growth of functional connections at 24 and 30 months of age and at the age of two years having a the DMN being functionally similar to adults, illustrated by long-range connections between the frontal cortex and posterior areas of the DMN (Bulgarelli et al., 2020). The medial prefrontal cortex, posterior cingulate cortex/retrosplenial, inferior parietal lobule, lateral temporal cortex, and hippocampal regions of the DMN are connected similarly to adults at two years of age (Gao et al., 2009). These changes take place up to the age of one year following subtle growth between first and second years (Bulgarelli et al., 2020). All areas of the DMN that originate at one year continue to two years of age with an inclusion of the parahippocampal cortex, resulting in a further complete DMN (Gao et al., 2009). At one year, the DMN becomes more complex with strong connections between regions of the 
brain, demonstrating an origin of a well synchronized DMN (Gao et al., 2009). The functional connectivity of the DMN follows an inverse U pattern, in which functional connectivity is highest in adulthood, and lowest in childhood and in the elderly (Mak et al., 2017).

\section{Default Mode Network Activity in Relation to the Task Positive Network}

The DMN works in an anticorrelated manner with another network known as the task positive network (TPN) (Alboitz et al., 2014). The TPN activates upon cognitive engagement (Aboitz et al., 2014) and sustained attention (Gerrits et al., 2019) and is comprised of the dorsolateral prefrontal cortex, inferior parietal cortex, and the supplementary motor area (Broyd et al., 2009). It is active during alertness which occurs while engaged in certain tasks and is also involved in response preparation and selection (Broyd et al., 2009).

There are multiple networks that make up the TPN (Norman et al., 2017). First one is the central executive network (CEN) which is composed of the dorsolateral prefrontal cortex, inferior frontal gyrus, lateral parietal and dorsal striato-thalamic areas (Norman et al., 2017). It is responsible for selecting stimuli and responses to reach certain goals and modifying performance during tasks that require sustained attention (Norman et al., 2017). The second is the ventral attention network (VAN), which is composed of the inferior frontal gyrus, and the third is the salience network which consists of the anterior insula and middle/dorsal anterior cingulate cortex which is responsible for identifying important stimuli, activating the CEN, and deactivating the DMN upon environmental demands (Normal et al., 2017). The salience network is essentially involved in switching between the TPN and the DMN (Chand et al., 2017). Finally, the dorsal attention network (DAN) is also associated with the TPN (Di \& Biswal, 2014) as well as the Cingulo-Upercular Network (CON) which consists of task positive regions (Barber et al., 2015). 
Furthermore, research has also suggested that regions of the Frontoparietal control network (FPN) mediate activity between the DMN and DAN (Di \& Biswal, 2014).

While positive correlations are associated with the combining of neural activity playing similar functions, anticorrelations are associated with segregating neural activities or processes of competing functions which is typically seen in patterns of activity between the DMN and TPN (Joshi et al., 2017). Anticorrelations are also viewed as having a negative synchrony or a negative functional connectivity which can be studied using neuroimaging techniques such as the fMRI (Chen et al., 2011).

\section{Involvement of the DMN in ADHD}

The DMN interference hypothesis states that inattentive symptoms of ADHD may be a result of inadequate suppression of the DMN during goal-directed cognitive processes (Mowinckel et al., 2017). An inability to efficiently suppress DMN activity causes a hyperactivity of the DMN which interferes with performance on tasks (Konrad \& Eickhoff, 2010). Individuals with ADHD have shown overactivation of the DMN (Norman et al., 2017) and strong connectivity in regions of the DMN (Sutoko et al., 2020). Abnormal functioning of the DMN is the main origin of task interference resulting in attentional problems (Kaboodvand et al., 2020). This results in a stronger DMN activation which is linked to reduced task performance in ADHD (Mohan et al., 2016).

There is a large body of research indicating a dysfunction of the DMN in ADHD. As such, one would assume that this would also result in a dysfunction of the TPN, which is indeed 
the case. Children with ADHD display atypical activation patterns when demands are placed on the frontal executive system upon performing a task (Voeller, 2004).

An impairment in the DMN is demonstrated in both children and adults with ADHD in which the patient is slow in deactivating the DMN and turning on the TPN (Alexandar \& Farely, 2018). In other words, ADHD patients display decreased activation of the task positive regions along with reduced deactivation of task negative regions i.e., the DMN, during various cognitive tasks in ADHD (Hilger \& Fiebach, 2019). This impairment is intensified with tasks that are more cognitively demanding (Alexandar \& Farely, 2018). An inability to regulate activities and interactions of the DMN and cognitive control networks has been thought of as the main cause of task interference which result in attentional problems (Kaboodvand et al., 2020). The association between the DMN and cognitive control networks may be a critical pathology in ADHD (Mohan et al., 2016). This systematic review will put a focus towards the activity of the DMN in ADHD and how the TPN/cognitive control networks are affected in relation to the DMN. Since recent research has demonstrated that the DMN can be modulated with methylphenidate treatment (Picon et al., 2018), the effects of methylphenidate on the DMN will also be examined.

\section{Objective and Hypothesis}

The objective of this systematic review was to examine the DMN and its interconnected task positive networks in ADHD and to assess if methylphenidate treatment may assist in normalizing the DMN activity. It was hypothesized that patients with ADHD display a hyper-connected DMN due to its hyperactivity, which results in underactivity of the task positive networks, or a reduced anticorrelation between the two opposing networks, characterized by increased functional connectivity between the DMN and TPN. It is also hypothesized that methylphenidate 
treatment will result in the suppression of the DMN along with a reduction in functional connectivity of the DMN. Examining the baseline neural circuitry in the disorder will help researchers and medical professionals understand the underlying cause of the symptoms expressed in ADHD and will provide a potential target for research on future treatments or interventions. The findings of this research may also be used to assist in the development of a potential neuroimaging-based diagnosis of ADHD.

\section{Methodology}

There is no review protocol registered for the present systematic review.

\section{Preferred Reporting Items for Systematic Reviews and Meta-Analysis (PRISMA)}

The Preferred Reporting Items for Systematic Reviews and Meta-Analysis (PRISMA) was used to report information and data throughout this systematic review. This system provides a reporting guideline for systematic reviews and meta-analyses. The major sections include how to report data and information in title, abstract, introduction, methods, results, and discussion. It also requires reporting of protocol and registration as well as stating funding sources. This reporting guideline allows researchers to develop methods such as the eligibility criteria, use of information source/databases, search strategy, study selection, data collection process, assessment of risk of bias, and data reporting. The following methodology utilized PRISMA as a guideline. 


\section{Eligibility Criteria}

To be eligible for the first part of the systematic review, the studies examining the resting state neural circuitry (inclusive of the DMN) in ADHD, met the following criteria:

\section{Inclusion Criteria}

1. Published in English in a peer-reviewed journal

2. An original article

3. Year of publication 2008 until present to collect a large number of studies, along with the consideration of newer procedures and techniques developed until present

4. Principal objective of an assessment of resting state neural circuitry in ADHD patients with DMN being a major component of the study exclusively, or in relation to the TPN. Inclusion was not be confined to studies exclusively examining the DMN and/or TPNS in ADHD. In other words, the outcome of interest can be primary or secondary.

5. An observational, case-controlled, between-subjects study

6. Inclusion of an age and gender-matched healthy control/comparison group

7. Main subjects of human participants with a primary diagnosis of ADHD (any subtype of ADHD i.e., inattentive, hyperactive/impulsive, or combined)

8. Clear demographics of the subjects that participated in the study including gender, age, ADHD subtypes, and treatment. These demographic variables were left open, with no specific exclusions.

9. Use of resting-state fMRI

10. Studies that used published datasets of resting-state fMRI were also included 


\section{Exclusion Criteria}

1. The exclusive use of structural neuroimaging

2. The use of a functional neuroimaging techniques other than resting-state fMRI

3. Review articles and meta-analyses

4. Animal studies

5. There were no exclusions based on age as all children, adolescent, and adult studies were included.

To be eligible for the second part of the systematic review, the studies examining the pharmacological effects of methylphenidate treatment on DMN activity, met the following criteria:

\section{Inclusion Criteria}

1. Published in English in a peer-reviewed journal

2. An original article

3. A primary study

4. Year of publication 2008 until present to collect a large number of studies, along with the consideration of newer procedures and techniques developed until present

5. Main subjects of human participants with a primary diagnosis of ADHD (any subtype of ADHD i.e., inattentive, hyperactive/impulsive, or combined)

6. An observational, case-controlled, and between-subjects study or a within-subjects study

7. One of the principal objectives being an assessment of the effects of methylphenidate treatment on DMN activity 
8. ADHD participants must be on methylphenidate treatment. May be on treatment for a long period of time, in which there should be a washout period, or may be given for the purpose of the experiment (with informed consent)

9. For the case-controlled, between-subjects study, there must be an age and gendermatched healthy control group. For the within-subjects study there is no need of a healthy control group

10. For all studies, there must be a neuroimaging procedure before and after the treatment to assess the effects of the pharmacological intervention

11. Clear demographics of the subjects that participated in the study including gender, age, ADHD subtypes and treatment

12. Use of a functional neuroimaging technique

\section{Exclusion Criteria}

1. The exclusive use of structural neuroimaging

2. Review articles and meta-analyses

3. Animal studies

4. There were no exclusions based on age as all children, adolescent, and adult studies were included

\section{Search Strategy}

The databases searched were PubMed, PsycINFO, and PsycARTICLES. 


\section{Keywords}

The key terms used were Attention Deficit Hyperactivity or ADHD, Default Mode

Network, Task Negative Network, Resting State Networks(s), Task Positive Network(s), and cognitive control networks. Search items with similar or related meanings were integrated using the OR terminology, and the search items were coupled using AND terminology. The resulting searches conducted using the databases were as follows.

Attention Deficit Hyperactivity Disorder OR ADHD AND the Default Mode Network OR Task Negative Network; Attention Deficit Hyperactivity Disorder OR ADHD AND Resting State Networks; Attention Deficit Hyperactivity Disorder OR ADHD AND Default Mode Network OR Task Negative Network AND Task Positive Networks; Attention Deficit Hyperactivity Disorder OR ADHD AND Resting State Networks AND Task Positive Networks; Attention Deficit Hyperactivity Disorder OR ADHD AND Default Mode Network OR Task Negative Network AND Cognitive Control Networks; Attention Deficit Hyperactivity Disorder OR ADHD AND Resting State Networks AND Cognitive Control Networks.

The use of older terminology such as Attention Deficit Disorder (ADD) was not included as potential search terms to allow a uniform comparison across studies of ADHD and to consider more current research.

The resulting outputs were recorded and inputted into reference management software. Duplicated, defined as the same article outputted more than once amongst searches, were removed. The software used for this systematic review was Mendeley. 


\section{Study Selection and Screening}

One investigator independently screened the literature using the following procedure:

The first screening phase was conducted by assessing titles and abstracts which should meet the research objective. Once passed, the article was screened and examined in full, making sure it matches all the eligibility criteria. If this stage was passed, the study was included in the systematic review. Any study that did not pass the inclusion criteria was excluded. The number of records in each step of the process was recorded. To illustrate the screening methods followed and the results obtained, a flow chart figure was constructed based on the PRISMA follow diagram (Figure 2).

\section{Data Extraction and Synthesis}

The following data was extracted from the studies of the first part of the systematic review: (1) the title of the study, (2) the authors and investigators involved in the study, (3) the year the study was published, (4) sample size of both the healthy control group and the ADHD group (5), participant characteristics (age, gender, ADHD subtype diagnosis, treatment), (6) summary/description of principle findings.

The following data was extracted from the studies of the second part of the systematic review:

(1) the title of the study, (2) the authors and investigators involved in the study, (3) the year the study was published, (4) sample size of both the healthy control group and the ADHD group (for case-controlled, between-subjects studies) (5), participant characteristics (age, gender, ADHD 
subtype diagnosis, treatment), (6) methylphenidate intervention and dose, (7) functional neuroimaging technique used, (8) summary/description of principle findings.

\section{Assessment of Risk of Bias}

The Joanna Briggs Institute (JBS) Critical Appraisal Checklist for Case Control Studies was utilized to assess risk of bias (Appendix A). Item numbers 1-5, and 8-10 had to at least be met to be included in the systematic review. In other words, they needed to score a minimum of 8/10.

\section{Results}

\section{Screening Results}

The initial search amongst the three databases, PubMed, PsychINFO, and PsychARTICLES, resulted in a total of 310 studies with a detection of 135 duplicates which were removed. This resulted in 175 studies. Out of the 175 studies screened, 101 studies were excluded due to not meeting the inclusion and exclusion criteria based on title and abstract screening. This led to fulltext article screening of 74 studies out of which 44 were excluded, resulting in the inclusion of a total of 30 studies (nT) in the qualitative synthesis/systematic review, 22 (n1) for the first part of the systematic review and $8(\mathrm{n} 2)$ for the second part of the systematic review. These results are illustrated in the PRISMA Flow Diagram in Figure 2.

Study and Participant Characteristics (Part 1: DMN Function in Patients with ADHD)

For the first part of the systematic review, the research studies included had a primary objective of examining the neural circuitry in patients with ADHD with the DMN being a large component of the study either exclusively or in relation to the TPNs. The resulting 22 studies were case controlled, between subject studies involving a healthy control group. Out of the 22 studies, 8 
studies used the ADHD-200 database for their neuroimaging data. All the studies used restingstate fMRI allowing a stronger comparison between studies. The sample sizes ranged from 15 to 256 for the clinical ADHD group, 15 to 251 for the healthy control group, resulting in total sample sizes of 30 to 490 participants. The participants' ages ranged from $8.39+/-1.89$ years to $34.9+/-9.90$ years for the clinical ADHD group and from $8.84+/-1.57$ years to $31.2+/-9.0$ years for the healthy control group, resulting in the inclusion of all children, adolescent, and adult studies. Furthermore, 4 studies included participants diagnosed with ADHD-C, 1 study with ADHD-I, 6 studies with both ADHD-C and ADHD-I, 3 studies with all ADHD-C, ADHDI, and ADHD-HI. Finally, 8 studies did not report data about ADHD subtypes. Medication data was not reported by 2 studies, partial medication data was reported by 3 studies, 6 studies included participants who were medication naïve and 11 studies included participants taking medication with washout ranging from 24 hours to 12 months, and 1 study requiring a washout of 5 half-lives. In one study the participants did not go through a washout of medications because their parents were concerned of possible consequences of discontinuing the medication (Chen et al., 2020).

Assessment of Risk of Bias

The full-text articles that were included in the systematic review scored a minimum of $8 / 10$ on the JBI Critical Appraisal Checklist (Appendix A).

\section{Functional Connectivity within The Default Mode Network}

A hypothesis of this systematic review was that hyperactivity of the DMN may be associated with hyperconnectivity of the DMN in patients with ADHD. Three research studies $(27.27 \%)$ confirmed this hypothesis by their findings of hyper-connectivity of the DMN in ADHD patients (Study \# 1-3). On the contrary, 5 research studies (45.45\%) found that patients with ADHD have reduced connectivity within 
the DMN (Study \# 4-8). There were also 3 studies (27.27\%) that obtained mixed findings of both increased and decreased functional connectivity in various DMN regions (Study \# 9-11). There were no studies that did not find any differences in the DMN connectivity between patients with ADHD and healthy controls. Detailed results illustrated in Table 1.

\section{Anticorrelated Activity Between the Default Mode and Task Positive Networks}

Another hypothesis of this systematic review was that patients with ADHD have reduced anticorrelation between the DMN and TPN. Consistent with this hypothesis, 7 studies (77.78\%) found a reduced anticorrelation between the DMN and TPNs or regions within those networks (Study \# 3, 7, 12, 13, 15-17). There was 1 study however that opposed this hypothesis (Study \# 1). In addition, there was 1 study that found no difference in negative connectivity/anticorrelation between the DMN and Executive Control Network in individuals with ADHD in comparison to healthy controls (Study \# 18). Detailed results illustrated in Table 1.

\section{Functional Connectivity Between the Default Mode and Task Positive Network}

In this systematic review it was also hypothesized that reduced anticorrelation between the DMN and TPN is associated with enhanced connectivity between the DMN and TPN regions. In line with this hypothesis, 3 studies (50\%) found increased connectivity/connectivity strength between the DMN and the TPN (Study \# 2, 8,12). In contrast to these findings, 1 study found reduced connectivity strength between the DMN and TPN regions (Study \# 13).

Interestingly, there was 1 study that found both increased and decreased functional connectivity between the default mode and task positive regions (study \# 11). However, distinct from all the above findings, 1 study found no significant difference in functional connectivity 
between any two of the networks between healthy controls and ADHD patients (Study \# 14).

Detailed results illustrated in Table 1.

\section{Additional Brain Activity Measures within The Default Mode Network}

The overall hypothesis proposed by this systematic review was that individuals with ADHD have altered activity of the DMN compared to healthy controls. Seven studies confirmed this hypothesis by measuring the DMN using various measures (Study \# 4-5, 12, 19-22).

Temporal variability is such a variable which reflects the reconfiguration of the brain into functional modules which predict flexibility and adaptability of the brain (Zhang et al., 2018). Individuals with ADHD have shown increased temporal variability in the DMN, compared to healthy controls (Zhang et al., 2018; Study \# 4). Consistent with this, Wang \& Li (2015) (Study \# 19) acquired results that illustrated increased Amplitude of Low Frequency Fluctuations (ALFFs), used to assess temporal activity, in the posterior DMN in the ADHD group which was positively correlated with symptoms of inattention.

Mean Square Successive Difference (MSSD) is another variable that can be used to measure DMN activity and is a measure of brain signal variability (Nomi et al., 2018). Nomi et al. (2018) (Study \# 20) found that a categorical analysis, a comparison between ADHD patients and healthy controls, resulted in no difference of MSSD between the two groups. However, a dimensional analysis, which examines the relationship between MSSD and ADHD symptom severity with and without ADHD, resulted in a positive correlation between MSSD and symptom severity of inattention in both groups. This positive correlation was associated with the Medial Prefrontal Cortex (mPFC) of the DMN. The MSSD was not correlated with hyperactivity.

A study conducted by Kaboodvand et al. (2020) (Study \# 5) also demonstrated altered activity in the DMN. They found that intra and inter-DMN network-network interactions display 
reduced stable cooperation between networks in those with ADHD. The stable cooperation was also found to be less frequent and shorter. Uddin et al. (2008) (Study \# 21) also found that network homogeneity, a measure of cohesiveness within functional networks, was reduced in the DMN in the ADHD group especially between the precuneus and DMN regions. They also found an altered connectivity of the precuneus. Furthermore, Hoekzema et al., (2014) (Study \# 12) found strong coherence and connectivity strength between the left DLPFC and regions of the DMN in those with ADHD which were correlated with selective attention, similar to findings of Kumar et al. (2020) (Study \# 22) whose results illustrated a strong coherence and enhanced coupling of the left dorsal Anterior Cingulate Cortex (dACC) with the DMN regions in the ADHD group. As we can see, DMN activity is altered in patients with ADHD as evident by examining the DMN function with these additional variables. Detailed results illustrated in Tables 1 and 2 .

Study and Participant Characteristics (Part 2: Effects of Methylphenidate Treatment on the Default Mode Network)

For the second part of the systematic review, the studies had a primary objective of examining the effects of methylphenidate on DMN activity in individuals with ADHD or healthy controls. From the resulting 8 studies, 4 studies were case-controlled between-subjects studies and 4 were within-subjects studies with 3 studies including only a clinical ADHD group and 1 study including only a healthy group. For all studies that had a clinical ADHD group, only the ADHD participants underwent the methylphenidate administration. In terms of the neuroimaging technique used, 4 studies used task-based fMRI, 2 studies used resting-state fMRI, and 2 studies used task-based EEG.

The sample sizes ranged from $11-40$ for the ADHD group and $11-34$ for the healthy control group resulting in total sample sizes to $15-41$. The ages ranged from $8.78+/-0.85$ to 
$30.67+/-7.41$ for the ADHD group and $9-15$ years +/- 6 months to $29.2+/-10.4$ years for the healthy control group, resulting in the inclusion of all children, adolescent, and adult studies.

For the ADHD patients that participated in the studies, 3 studies used all patients with ADHD-C, 2 studies used patients with ADHD-C or ADHD-I, and 2 studies did not indicate ADHD subtype data. Medication status was reported by all studies with 5 studies using ADHD patients who are medication naïve, 1 study with ADHD patients who are all on medication (washout period of 36 hours), and 1 study with some ADHD patients on medication (washout period of 1 month).

\section{Effects of Methylphenidate Treatment on the Default Mode Network}

A final hypothesis proposed by this systematic review was that methylphenidate treatment would result in a 'normalization' or a reduction in DMN activity and reduced functional connectivity of the DMN in patients with ADHD. For the studies that were looking into DMN activity, all of the studies (Study \# 23-27) found that methylphenidate treatment results in a suppression of DMN activity upon cognitive engagement, supporting the hypothesis. In addition, one study (Study \# 28) that looked in functional connectivity, found that functional connectivity of the frontalprefrontal regions is reduced, which may be due to a reduction of DMN activity (Silberstein et al., 2017). All of the above studies measured differences in DMN activity by methylphenidate treatment in individuals with ADHD while performing cognitive tasks (task-based fMRI).

Two studies measured the effects of methylphenidate treatment on the DMN in a resting state (resting-state fMRI). It was discovered that methylphenidate treatment increases functional connectivity between two nodes of the DMN, the PCC and the left lateral parietal cortex (Study \# 29). Moreover, there was one study that found no significant differences in connectivity 
between regions of the DMN with methylphenidate treatment, with a relatively low increase in the anterior and posterior DMN. However, a significant increase in connectivity was seen between the putamen and DMN, which was correlated with a reduction in symptoms (Study \# 30). As predicted, methylphenidate treatment has a major impact on the function of the DMN, more specifically a suppression of DMN activity, in patients with ADHD. Detailed Results illustrated in Table 3. 
Figure 2: Screening Results

PRISMA 2009 Flow Diagram

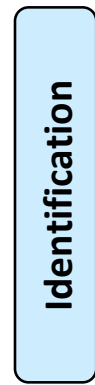

Records identified through database searching

$(n=310)$

Additional records identified through other sources

$$
(n=0)
$$
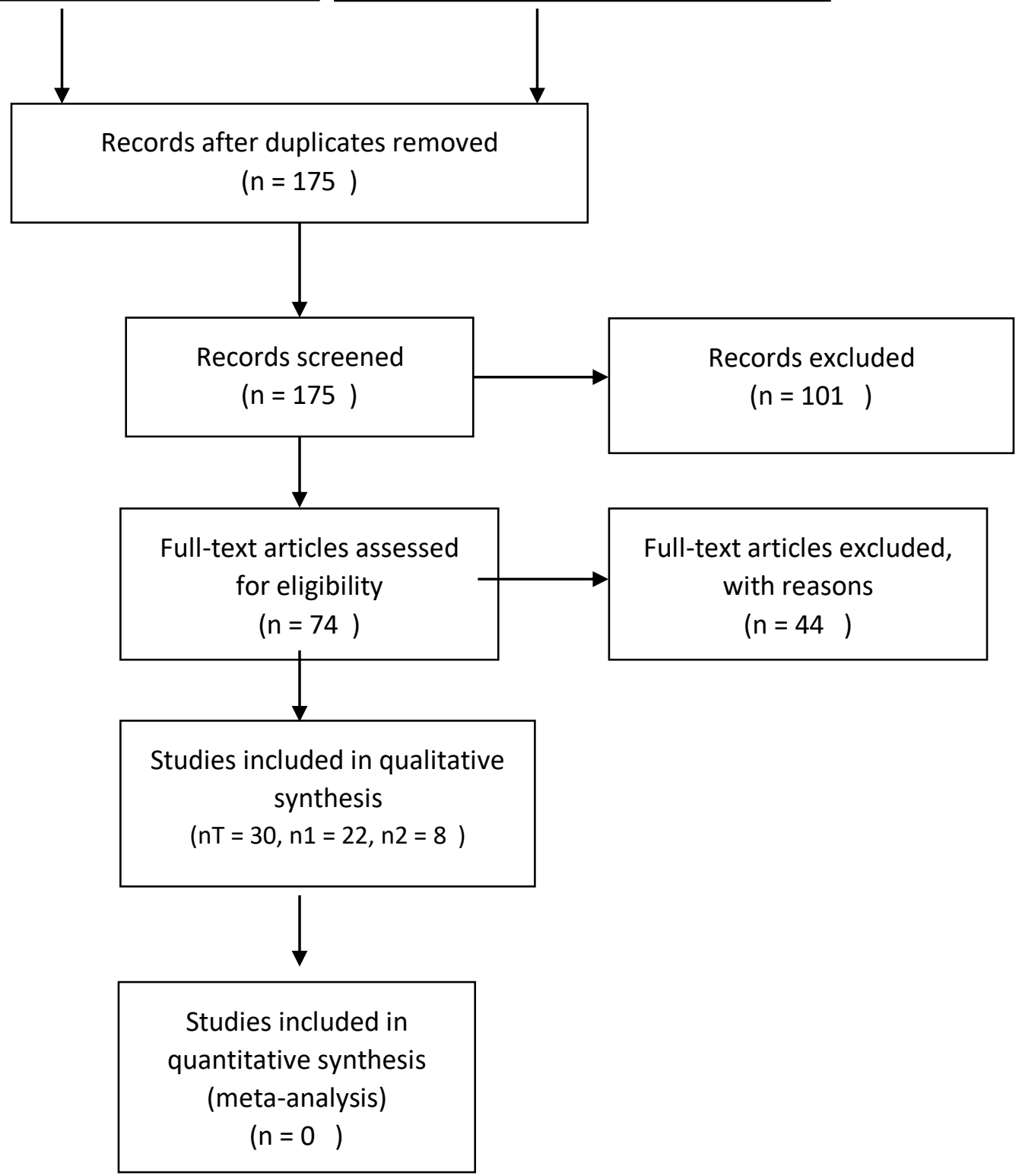
Table 1: Functional Connectivity and Activity within and Between The Default Mode and Task Positive Network Abbreviations: M: Males; F: Females; HC: Healthy Controls; DMN: Default Mode Network; CON: Cingulo-Opercular Network; VAN: Ventral Attention Network; FC: Function Connectivity; PCC: Posterior Cingulate Cortex; FPN: Frontoparietal Network; dACC: Dorsal Anterior Cingulate Cortex; aCC: Anterior Cingulate Cortex; SN: Salience Network; ECN: Executive Control Network; TPN: Task Positive Network; PFC: Prefrontal Cortex; MFC: Medial Frontal Cortex; IFG: Inferior Frontal Gyrus; mPFC: Medial Prefrontal Cortex; DLPFC: Dorsolateral Prefrontal Cortex; CEN: Central Executive Network; DMPFC: Dorsomedial PFC; MFG: Medial Frontal Gyrus

\begin{tabular}{|c|c|c|c|c|}
\hline Study \# & Title, Author (s), Year & $\begin{array}{l}\text { Sample } \\
\text { Size } \\
\text { (nADHD, } \\
\text { nHC, } \\
\text { nTotal) } \\
\end{array}$ & $\begin{array}{l}\text { Participant Characteristics (Gender, mean } \\
\text { age/age range, ADHD subtypes, treatment } \\
\text { status) }\end{array}$ & Principle Default Mode Network-Related Finding \\
\hline 1 & $\begin{array}{lr}\text { Connectivity } & \text { Supporting } \\
\text { Attention in Children with } \\
\text { Attention } & \text { Deficit } \\
\text { Hyperactivity } & \text { Disorder } \\
\text { (Barber et al., 2015) }\end{array}$ & $\begin{array}{l}\mathrm{nADHD}= \\
50 \\
\mathrm{nHC}=50 \\
\text { nTotal }= \\
100\end{array}$ & $\begin{array}{l}\text { ADHD: } 32 \mathrm{M} / 18 \mathrm{~F} \text {, mean age }=9.81 / 8-12 \text { years, } \\
39 \text { ADHD-C, } 1 \text { ADHD-HI, } 10 \text { ADHD-I, } 35 \text { on } \\
\text { stimulant medication, asked to discontinue } 24 \mathrm{~h} \\
\text { before testing } \\
\text { HC: } 31 \mathrm{M} / 19 \mathrm{~F}, 9.99 / 8-12 \text { years }\end{array}$ & $\begin{array}{l}\text { ADHD group displayed hyperconnectivity within the DMN and CON. Greater anticorrelation between } \\
\text { CON and DMN linked to stronger within-network connectivity, especially the DMN. }\end{array}$ \\
\hline 2 & $\begin{array}{l}\text { Functional Connectivity of } \\
\text { Attention-Related Networks } \\
\text { in Drug-Native Children with } \\
\text { ADHD (Lin et al., 2018) }\end{array}$ & $\begin{array}{l}\text { nADHD = } \\
46 \\
\text { nHC = } 31 \\
\text { nTotal = } \\
77\end{array}$ & $\begin{array}{l}\text { ADHD: } 39 \mathrm{M} / 7 \mathrm{~F} \text {, mean age }=8.39+/-1.95 \\
\text { years, } 22 \mathrm{ADHD}-\mathrm{I}, 3 \mathrm{ADH}-\mathrm{HI}, 21 \mathrm{ADHD}-\mathrm{C} \text {, } \\
\text { drug naïve } \\
\text { HC: } 22 \mathrm{M} / 9 \mathrm{~F} \text {, mean age }=9.23+/-1.82 \text { years }\end{array}$ & $\begin{array}{l}\text { ADHD group showed hyperconnectivity within the DMN and between DAN and DMN regions. No } \\
\text { significant } \\
\text { alteration }\end{array}$ \\
\hline 3 & $\begin{array}{l}\text { Topological Data Analysis } \\
\text { Reveals Robust Alterations in } \\
\text { the Whole-Brain Frontal } \\
\text { Lobe Functional } \\
\text { Connectomes in Attention- } \\
\text { Deficit/Hyperactivity } \\
\text { Disorder (Gracia-Tabuenca et } \\
\text { al., 2020) }\end{array}$ & $\begin{array}{l}\text { ADHD- } \\
200 \\
\text { Database } \\
\text { nADHD = } \\
81 \\
\text { nHC }=96 \\
\text { nTotal = } \\
177\end{array}$ & $\begin{array}{l}\text { ADHD: } 59 \mathrm{M} / 22 \mathrm{~F} \text {, age }=10.5+/-2.48 \text {, } \\
\text { medication naïve, ADHD subtype data not } \\
\text { available } \\
\text { HC: } 45 \mathrm{M} / 51 \mathrm{~F} \text {, age }=12.26+/-3.07\end{array}$ & $\begin{array}{l}\text {-Reduced functional segregation/anticorrelation in the ADHD group, mainly associated with the frontal } \\
\text { lobe and DMN } \\
\text {-Increased FC especially in regions of the frontal lobe and DMN }\end{array}$ \\
\hline 4 & $\begin{array}{l}\text { Neural, Electrophysiological } \\
\text { and Anatomical Basis of } \\
\text { Brain-Network Variability } \\
\text { and its Characteristic } \\
\text { Changes in Mental Disorders } \\
\text { (Zhang et al., 2018) }\end{array}$ & $\begin{array}{l}\text { Used } 2 \\
\text { datasets of } \\
\text { ADHD- } \\
200 \\
\text { Database } \\
\text { nADHD = } \\
99+140 \\
=239 \\
\text { nHC = 143 } \\
+108= \\
251 \\
\text { nTotal = } \\
490\end{array}$ & $\begin{array}{l}\text { ADHD: } 89 \mathrm{M} / 10 \mathrm{~F}, \text { age }=12.1+/-2.0 \& 106 \mathrm{M} \\
/ 34 \mathrm{~F}, \text { age }=11.1+/-2.7 .98 \text { participants } \\
\text { medicated, 55 not medicated, remaining } \\
\text { subjects lacked information about medication } \\
\text { use, ADHD subtype data not available. } \\
\mathrm{HC}: 84 \mathrm{M} / 59 \mathrm{~F} \text {, age }=11.4+/-1.9 \& 54 \mathrm{M} / 54 \\
\mathrm{~F}, \text { age }=12.2+/-3.1\end{array}$ & $\begin{array}{l}\text {-DMN temporal variability in ADHD higher than } \mathrm{HC} \\
\text {-Low FC of DMN regions such as the PCC }\end{array}$ \\
\hline
\end{tabular}




\begin{tabular}{|c|c|c|c|c|}
\hline 5 & $\begin{array}{l}\text { Dynamic } \\
\text { Configurations of Resting- } \\
\text { State Networks in ADHD } \\
\text { (Kaboodvand et al., 2020) }\end{array}$ & $\begin{array}{l}\text { nADHD = } \\
39 \\
\text { nHC }=116 \\
\text { nTotal = } \\
155\end{array}$ & $\begin{array}{l}\text { ADHD: } 20 \mathrm{M} / 19 \mathrm{~F}, \text { mean age }=31.59+/-10.12 \text {, } \\
\text { non-medicated for minimum } 12 \text { months, ADHD } \\
\text { subtype data not available } \\
\text { HC: } 63 \mathrm{M} / 53 \mathrm{~F} \text {, mean age }=31.0 .5+/-8.64\end{array}$ & 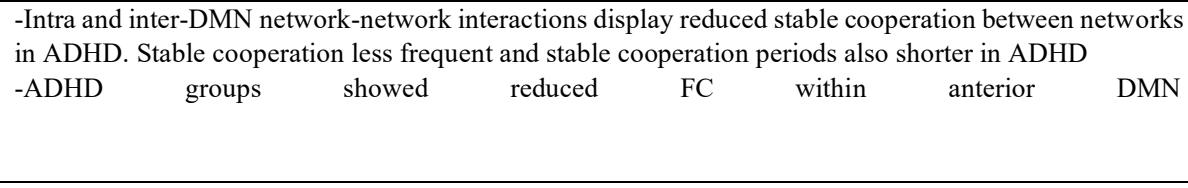 \\
\hline 6 & $\begin{array}{l}\text { Disrupted Control-Related } \\
\text { Functional Brain Networks in } \\
\text { Drug-Naïve Children with } \\
\text { Attention- } \\
\text { Deficit/Hyperactivity } \\
\text { Disorder (Tao et al., 2017) }\end{array}$ & $\begin{array}{l}\text { nADHD = } \\
46 \\
\text { nHC = } 31 \\
\text { nTotal = } \\
77\end{array}$ & $\begin{array}{l}\text { ADHD: } 38 \mathrm{M} / 8 \mathrm{~F} \text {, mean age }=8.48+/-1.89 \text {, } \\
\text { medication naïve, ADHD subtype data not } \\
\text { available } \\
\text { HC: } 22 \mathrm{M} / 9 \mathrm{~F} \text {, mean age }=8.84+/-1.57\end{array}$ & $\begin{array}{l}\text { ADHD: Significantly reduced FC in regions of the } \mathrm{DMN} \text { and FPN, particularly the inferior parietal lobe, } \\
\text { precuneus, intraparietal sulcus, superior frontal cortex, anterior prefrontal cortex, dorsal anterior } \\
\text { cingulate/medial superior frontal cortex, and lateral cerebellum. }\end{array}$ \\
\hline 7 & $\begin{array}{l}\text { Cingulate-Precuneus } \\
\text { Interactions: A New Locus of } \\
\text { Dysfunction in Adult } \\
\text { Attention- } \\
\text { Deficit/Hyperactivity } \\
\text { Disorder (Castellanos et al., } \\
\text { 2008) }\end{array}$ & $\begin{array}{l}\text { nADHD }= \\
20 \\
\text { nHC }=20 \\
\text { nTotal }= \\
40\end{array}$ & $\begin{array}{l}\text { ADHD: } 16 \mathrm{M} / 4 \mathrm{~F} \text {, mean age }=34.9+/-9.9 \\
\text { years, all ADHD-C, no history of psychotropics } \\
\text { other than stimulants. } 9 \text { treated with stimulants, } \\
\text { discontinued at least } 24 \mathrm{~h} \text { prior to testing } \\
\text { HC: } 14 \mathrm{M} / 6 \mathrm{~F} \text {, mean age }=31.2+/-9.0\end{array}$ & $\begin{array}{l}\text { Anti-correlated activity between the dACC (TPN region) and DMN abnormal in ADHD patients. Reduced } \\
\text { FC between aCC and precuenus/PCC areas, and reduced FC between precuneus and other DMN regions } \\
\text { inclusive of the ventromedial PFC and areas of the PCC. Significantly reduced anti-correlated activity } \\
\text { between the dACC } \quad \text { and the precuneus }\end{array}$ \\
\hline 8 & $\begin{array}{l}\text { Novel Subgroups of } \\
\text { Attention- } \\
\text { Deficit/Hyperactivity } \\
\text { Disorder Identified By } \\
\text { Topological Data Analysis } \\
\text { and Their Functional } \\
\text { Network Modular } \\
\text { Organizations (Kyeong et al., } \\
\text { 2017) }\end{array}$ & $\begin{array}{l}2 \text { datasets } \\
\text { of ADHD- } \\
200 \\
\text { Database } \\
\text { nADHD = } \\
67+91= \\
158 \\
\text { nHC: } 62+ \\
43=105 \\
\text { nTotal = } \\
263\end{array}$ & $\begin{array}{l}\text { ADHD: All male, [27 ADHD-C, } 40 \text { ADHD-I] } \\
\text { and [61 ADHD-C, } 28 \text { ADHD-I], mean age }= \\
12.4+/-1.9 \text { and } 11.4+/-2.7 \text {, treatment status } \\
\text { data not available } \\
\text { HC: All male, mean age }=12.1+/-1.6 \text { and } 11.7 \\
+/-3.2 \text { years }\end{array}$ & $\begin{array}{l}\text {-ADHD group: inter-module functional connectivity density (FCD) in DMN-SN significantly increased } \\
\text { in both mild and severe ADHD groups. Intra-module FCD within DMN significantly decreased in severe } \\
\text { ADHD group. } \\
\text {-ADHD group showed increased inter-module connectivity between the DMN and ECN (subnetwork of } \\
\text { TPN (Daniels et al., 2010)), in the severe ADHD group and not the mild ADHD group }\end{array}$ \\
\hline 9 & $\begin{array}{l}\text { Changes of Brain structure } \\
\text { and Function in ADHD } \\
\text { Children (Qiu et al., 2011) }\end{array}$ & $\begin{array}{l}\text { nADHD = } \\
15 \\
\text { nHC }=15 \\
\text { nTotal }= \\
30\end{array}$ & $\begin{array}{l}\text { ADHD: All male, mean age }=12.65+/-1.82 \text {, all } \\
\text { ADHD-I, medication free for minimum } 6 \\
\text { months } \\
\text { HC: All male, mean age }=13.21+/-1.73\end{array}$ & $\begin{array}{l}\text {-ADHD subjects displayed both increased and decreased FC in various DMN regions } \\
\text {-Significantly reduced FC in the aCC, PCC, lateral PFC, left precuneus and thalamus, and increased FC } \\
\text { in bilateral posterior MFC in the DMN }\end{array}$ \\
\hline 10 & $\begin{array}{l}\text { Structural and Functional } \\
\text { Connectivity in Children and } \\
\text { Adolescents with and } \\
\text { Without Attention } \\
\text { Deficit/Hyperactivity } \\
\text { Disorder (Bos et al., 2017) }\end{array}$ & $\begin{array}{l}\mathrm{nADHD}= \\
35 \\
\mathrm{nHC}=36 \\
\text { nTotal }= \\
71\end{array}$ & $\begin{array}{l}\text { ADHD: } 26 \mathrm{M} / 9 \mathrm{~F} \text {, mean age }=11.2+/-2.6,27 \\
\text { using stimulant medication, } 8 \text { medication naïve. } \\
\text { Stimulant medication discontinued } 24 \mathrm{~h} \text { prior to } \\
\text { scanning. ADHD subtype data not available } \\
\text { HC: } 29 \mathrm{M} / 7 \mathrm{~F} \text {, age: } 12.1+/-2.2\end{array}$ & $\begin{array}{l}\text { ADHD subjects displayed increased FC in the right IFG and right mPFC of the DMN and a small cluster } \\
\text { of decreased FC in the right PCC of the DMN }\end{array}$ \\
\hline 11 & $\begin{array}{l}\text { Functional Connectivity of } \\
\text { Specific Brain Networks } \\
\text { Related to Social and }\end{array}$ & $\begin{array}{l}\mathrm{nADHD}= \\
18\end{array}$ & $\begin{array}{l}\text { ADHD: } 13 \mathrm{M} / 5 \mathrm{~F} \text {, mean age }=13.56+/-1.72 \\
\text { years, } 9 \text { ADHD-C, } 9 \text { ADHD-I, half treated }(\mathrm{n}=\end{array}$ & $\begin{array}{l}\text {-ADHD: Increased FC within the ventromedial PFC of the DMN and reduced FC within the precuneus of } \\
\text { the DMN }\end{array}$ \\
\hline
\end{tabular}




\begin{tabular}{|c|c|c|c|c|}
\hline & $\begin{array}{l}\text { Communication Dysfunction } \\
\text { in Adolescents with } \\
\text { Attention-Deficit } \\
\text { Hyperactivity Disorder (Chen } \\
\text { et al., 2020) }\end{array}$ & $\begin{array}{l}\mathrm{nHC}=16 \\
\text { nTotal }= \\
34\end{array}$ & $\begin{array}{l}8 \text { with methylphenidate and } \mathrm{n}=1 \text { with } \\
\text { atomoxetine) } \\
\text { HC: } 8 \mathrm{M} / 8 \mathrm{~F} \text {, mean age }=14.06+/-1.53 \text { years }\end{array}$ & $\begin{array}{l}\text {-Increased FC between DMN (ventromedial PFC) and CON (anterior insula), and between FPN (DLPFC), } \\
\text { and CON, but reduced FC between DMN (PCC) and FPN (inferior parietal lobe), and between DMN } \\
\text { (precuneus) and CON (temporoparietal junction) } \\
\text {-Functional dysconnectivity between the DMN, FPN, CON }\end{array}$ \\
\hline 12 & $\begin{array}{l}\text { An Independent Components } \\
\text { and Functional Connectivity } \\
\text { Analysis of Resting State } \\
\text { fMRI Data Points to Neural } \\
\text { Network Dysregulation in } \\
\text { Adult ADHD (Hoekzema et } \\
\text { al., 2014) }\end{array}$ & $\begin{array}{l}\text { nADHD = } \\
22 \\
\text { nHC }=23 \\
\text { nTotal }= \\
45\end{array}$ & $\begin{array}{l}\text { ADHD: All male, all ADHD-C, mean age }= \\
32.82+/-10.75 \text { years, medication naïve } \\
\text { HC: All male, mean age }=29.26+/-8.92\end{array}$ & $\begin{array}{l}\text {-ADHD: strong coherence of left DLPFC (TPN region) with DMN components which were correlated } \\
\text { with selective attention } \\
\text {-High connectivity strength of left DLPFC with DMN regions } \\
\text {-Decreased anticorrelation between DMN (especially precuneus) and the DLPFC } \\
\text {-Weaker segregation between cognitive control networks and DMN }\end{array}$ \\
\hline 13 & $\begin{array}{l}\text { Functional Connectivity in } \\
\text { Cortico-Subcortical Brain } \\
\text { Networks Underlying } \\
\text { Reward Processing in } \\
\text { Attention- } \\
\text { Deficit/Hyperactivity } \\
\text { Disorder (Oldehinkel et al., } \\
2016 \text { ) }\end{array}$ & $\begin{array}{l}\text { ADHD- } \\
200 \\
\text { Database } \\
\text { nADHD = } \\
169 \\
\text { nHC = } 122 \\
\text { nTotal = } \\
291\end{array}$ & $\begin{array}{l}\text { ADHD: } 123 \mathrm{M} / 46 \mathrm{~F} \text {, mean age }=17.89 \text { years, } \\
83 \mathrm{ADHD}-\mathrm{I}, 17 \mathrm{ADHD}-\mathrm{HI}, 69 \text { ADHD-C, } 130 \\
\text { on stimulant medication, asked to discontinue } \\
48 \mathrm{hr} \text { prior to scanning } \\
\text { HC: } 54 \mathrm{M} / 68 \mathrm{~F} \text {, mean age }=17.04 \text { years }\end{array}$ & $\begin{array}{l}\text { Low connectivity strength for functional connections between DMN and TPN regions and reduced } \\
\text { anticorrelation between DMN and TPN }\end{array}$ \\
\hline 14 & $\begin{array}{l}\text { Aberrant Time-Varying } \\
\text { Cross-Network Interactions } \\
\text { in Children with Attention- } \\
\text { Deficit/Hyperactivity } \\
\text { Disorder and the Relation to } \\
\text { Attention Deficits (Cai et al., } \\
2018 \text { ) }\end{array}$ & 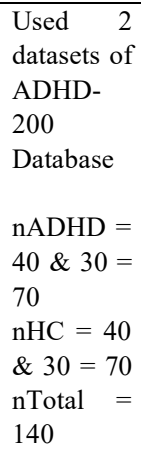 & $\begin{array}{l}\text { ADHD: } 27 \mathrm{M} / 13 \mathrm{~F} \& 30 \mathrm{M} / 0 \mathrm{~F} \text {, mean age }= \\
11.7 \& 12.6,11 \text { medication naïve, } 8 \text { medication } \\
\text { non-naïve, medical status for remaining } \\
\text { participants unavailable (additional analysis } \\
\text { performed to illustrate that findings are not } \\
\text { confounded by medication status). Subtype data } \\
\text { not available } \\
\text { HC: } 23 \mathrm{M} / 17 \mathrm{~F} \text { and } 30 \mathrm{M} / 0 \mathrm{~F} \text {, mean age }=11.9 \\
+/-3.2 \& 12.3+/-1.5\end{array}$ & $\begin{array}{l}\text { FC between any two of SN, CEN and DMN not different between HC and ADHD group, though SN- } \\
\text { centered interactions with DMN and CEN predict inattention in ADHD children }\end{array}$ \\
\hline 15 & $\begin{array}{l}\text { Abnormal } \text { Functional } \\
\text { Connectivity Between the } \\
\text { Anterior Cingulate Cortex } \\
\text { and the Default Mode } \\
\text { Network in Drug-Naïve Boys } \\
\text { with Attention Deficit } \\
\text { Hyperactivity Disorder (Sun } \\
\text { et al., 2012) }\end{array}$ & $\begin{array}{l}\text { nADHD }= \\
19 \\
\text { nHC }=23 \\
\text { nTotal }= \\
42\end{array}$ & $\begin{array}{l}\text { ADHD: All male, mean age }=13.28 / 11-16 \\
\text { years, } 12 \text { ADHD-I, } 7 \text { ADHD-C medication } \\
\text { naïve } \\
\text { HC: All male, mean age }=13.20 / 11-16 \text { years }\end{array}$ & $\begin{array}{l}\text {-Weaker segregation between cognitive control regions and regions of the DMN in ADHD } \\
\text {-dACC displayed significantly reduced negative FC/anticorrelation with the DMN (DMPFC and PCC) in } \\
\text { ADHD. }\end{array}$ \\
\hline 16 & $\begin{array}{l}\text { Shared Alterations in } \\
\text { Resting-State Brain } \\
\text { Connectivity in Adults with } \\
\text { Attention- }\end{array}$ & $\begin{array}{l}\text { nADHD = } \\
20 \\
\text { nADHD } \\
1^{\text {st }} \text { degree }\end{array}$ & $\begin{array}{l}\text { ADHD: } 17 \mathrm{M} / 3 \mathrm{~F}, 16 \text { ADHD-C, } 4 \text { ADHD-I, } \\
\text { mean age }=32.20+/-10.31 \text { years, } 16 \text { medicated } \\
\text { with methylphenidate (asked to discontinue for } \\
\text { 24h) and } 4 \text { non-medicated }\end{array}$ & $\begin{array}{l}\text {-Alterations in default mode connectivity in ADHD } \\
\text {-Decreased anticorrelations between PCC/precuneus and right MFG, associated with cognitive control } \\
\text { networks, in individuals with ADHD and their } 1^{\text {st }} \text { degree relatives. } \\
\text {-DMN connectivity linked to ADHD symptoms }\end{array}$ \\
\hline
\end{tabular}




\begin{tabular}{|c|c|c|c|c|}
\hline & $\begin{array}{l}\text { Deficit/Hyperactivity } \\
\text { Disorder and Their } \\
\text { Unaffected First-Degree } \\
\text { Relatives (Pironti et al., 2019) }\end{array}$ & $\begin{array}{l}\text { relatives = } \\
20 \\
\mathrm{nHC}=20 \\
\text { nTotal = } \\
60\end{array}$ & $\begin{array}{l}1^{\text {st }} \text { degree relatives: } 10 \mathrm{M} / 10 \mathrm{~F} \text {, mean age }= \\
38.85+/-15.31 \text { years } \\
\text { HC: } 13 \mathrm{M} / 7 \mathrm{~F} \text {, mean age }=32.5+/-5.8 \text { years }\end{array}$ & \\
\hline 17 & 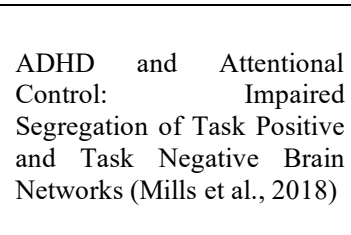 & $\begin{array}{l}\text { nADHD } \\
=256 \\
\text { nHC }=176 \\
\text { nTotal = } \\
432 \text { with } \\
604 \text { scans }\end{array}$ & $\begin{array}{l}\text { ADHD: } 181 \mathrm{M} / 75 \mathrm{~F} \text {, mean age }=11.05+/-1.58 \\
\text { years. Participants taking psychostimulants } \\
\text { were also included after a minimum } 5 \text { half-lives } \\
\text { washout. ADHD subtype data not available } \\
\text { HC: } 89 \mathrm{M} / 87 \mathrm{~F} \text {, mean age }=10.67+/-1.53 \text { years }\end{array}$ & $\begin{array}{l}\text { ADHD patients had reduced negative connectivity/anticorrelation between the TPN and DMN which } \\
\text { becomes more negative with age. Females showed increased negative connectivity }\end{array}$ \\
\hline 18 & $\begin{array}{l}\text { Inconsistency in Abnormal } \\
\text { Functional Connectivity } \\
\text { Across Datasets of ADHD- } \\
200 \text { in Children with } \\
\text { Attention Deficit } \\
\text { Hyperactivity Disorder (Zhou } \\
\text { et al., 2019) }\end{array}$ & 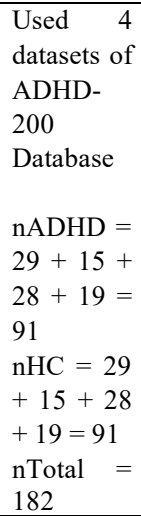 & $\begin{array}{l}\text { ADHD: All male, [19 ADHD-C, } 10 \text { ADHD-I], } \\
\text { [6 ADHD-C, } 9 \text { ADHD-I], [12 ADHD-C, } 16 \\
\text { ADHD-I], [7 ADHD-C, } 12 \text { ADHD-I], mean age } \\
=[12.1+/-2.9],[11.2+/-2.3],[12.7+/-1.7] \text {, } \\
\text { [13.3 +/- } 1.0], \text { medication withheld minimum } \\
\text { 24h prior to testing } \\
\text { HC: All male, }[12.2+/-2.8],[11.6+/-1.5],[11.7 \\
+/-1.8],[13.3+/-1.0]\end{array}$ & $\begin{array}{l}\text { ADHD group did not display abnormal FC between the DMN and ECN (part of TPN) i.e. no significant } \\
\text { difference of negative connectivity/anticorrelation between the ADHD and HC group }\end{array}$ \\
\hline
\end{tabular}


Table 2: Additional Brain Activity Measures within The Default Mode Network in ADHD Patients Abbreviations: M: Males; F: Females; HC: Healthy Controls; DMN: Default Mode Network; ALFFs: Amplitude of Low Frequency Fluctuations; ICN: Intrinsic Control Network; MSSD: Mean Square Successive Difference; mPFC: medial Prefrontal Cortex; dACC: Dorsal Anterior Cingulate Cortex

\begin{tabular}{|c|c|c|c|c|}
\hline Study \# & Title, Author (s), Year & $\begin{array}{l}\text { Sample } \\
\text { Size } \\
\text { (nADHD, } \\
\text { nHC, } \\
\text { nTotal) }\end{array}$ & $\begin{array}{l}\text { Participant Characteristics (Gender, mean } \\
\text { age/age range, ADHD subtypes, treatment } \\
\text { status) }\end{array}$ & Principle Default Mode Network-Related Finding \\
\hline 19 & $\begin{array}{l}\text { Altered Temporal Features of } \\
\text { Intrinsic } \text { Connectivity } \\
\text { Networks in Boys with } \\
\text { Combined Type Attention } \\
\text { Deficit } \quad \text { Hyperactivity } \\
\text { Disorder (Wang \& Li, 2015) }\end{array}$ & $\begin{array}{l}\text { ADHD- } \\
200 \\
\text { Database } \\
\text { nADHD = } \\
36 \\
\text { nHC = } 36 \\
\text { nTotal = } \\
72\end{array}$ & $\begin{array}{l}\text { ADHD: All male, mean age }=11.04+/-2.74 \text {, all } \\
\text { ADHD-C, treatment data not available } \\
\text { HC: All male, mean age }=11.83+/-2.88\end{array}$ & $\begin{array}{l}\text {-ADHD group displayed increased activated network-wise ALFFs in attention and DMN-related networks } \\
\text { compared to HC. Temporal patterns within posterior DMN positively correlated with inattention } \\
\text { symptoms. Fusiform related-DMN and attention-related networks negatively correlated with Intelligent } \\
\text { Quotient } \\
\text {-Enhanced temporal activity in DMN-associated ICNs }\end{array}$ \\
\hline 20 & $\begin{array}{l}\text { Resting-State Brain Signal } \\
\text { Variability in Prefrontal } \\
\text { Cortex is Associated with } \\
\text { ADHD Symptom Severity in } \\
\text { Children (Nomi et al., 2018) }\end{array}$ & $\begin{array}{l}\text { ADHD- } \\
200 \\
\text { Database } \\
\text { nADHD = } \\
40 \\
\text { nHC }=30 \\
\text { nTotal = } \\
70\end{array}$ & $\begin{array}{l}\text { ADHD: } 27 \mathrm{M} / 13 \mathrm{~F} \text {, mean age }=9.91+/-1.24 \\
\text { years, } 27 \text { ADHD-C, } 13 \text { ADHD-I, } 4 \text { on } \\
\text { medication, medication status unavailable for } \\
26 \text { ADHD subjects } \\
\text { HC: } 16 \mathrm{M} / 14 \mathrm{~F} \text {, mean age }=9.43 / 7-12 \text { years }\end{array}$ & $\begin{array}{l}\text {-Categorical analysis: no differences in MSSD between ADHD and HC. } \\
\text {-Dimensional analysis: positive correlation between MSSD and ADHD symptom severity and inattention } \\
\text { in both } \quad \text { groups. Seen in DMN regions } \\
\text {-MSSD not correlated with hyperactivity } \\
\text {-Differences in brain signal variability of network nodes within the DMN at rest }\end{array}$ \\
\hline 21 & $\begin{array}{l}\text { Network Homogeneity } \\
\text { Reveals Decreased Integrity } \\
\text { of Default- } \\
\text { Mode Network in ADHD } \\
\text { (Uddin et al., 2008) }\end{array}$ & $\begin{array}{l}\mathrm{nADHD}= \\
20 \\
\mathrm{nHC}=20 \\
\text { nTotal }= \\
40\end{array}$ & $\begin{array}{l}\text { ADHD: } 16 \mathrm{M} / 4 \mathrm{~F} \text {, mean age }=34.9+/-9.9 \text {, all } \\
\text { ADHD-C, } 9 \text { participants taking stimulants } \\
\text { (asked to discontinue } 24 \mathrm{~h} \text { prior to testing) } \\
\text { HC: } 14 \mathrm{M} / 6 \mathrm{~F} \text {, mean age }=31.2+/-9.0 \text { years }\end{array}$ & $\begin{array}{l}\text {-Decreased network homogeneity in the DMN in ADHD individuals compared to HC, especially between } \\
\text { the precuneus and other DMN areas. } \\
\text {-Altered connectivity of the precuneus shown by reduced homogeneity } \\
\text {-Reduced integrity of DMN }\end{array}$ \\
\hline 22 & $\begin{array}{l}\text { Neural Network Connectivity } \\
\text { in ADHD Children: An } \\
\text { Independent Component and } \\
\text { Functional Connectivity } \\
\text { Analysis of Resting State } \\
\text { fMRI Data (Kumar et al., } \\
\text { 2020) }\end{array}$ & $\begin{array}{l}\mathrm{nADHD}= \\
16 \\
\mathrm{nHC}=16 \\
\text { nTotal = } \\
32\end{array}$ & $\begin{array}{l}\text { ADHD: All male, mean age }=9.6+/-1.8 \text { years, } \\
\text { non-medicated, ADHD subtype data not } \\
\text { available } \\
\text { HC: All male, mean age }=9.7+/-1.9 \text { years }\end{array}$ & Strong coherence + enhanced coupling of left dACC with DMN regions in ADHD group \\
\hline
\end{tabular}


Table 3: The Effects of Methylphenidate on The Default Mode Network

Abbreviations: M: Males; F: Females; HC: Healthy Controls; DMN: Default Mode Network; TPN: Task Positive Network; MPH: Methylphenidate; ATX: Atomoxetine; DLPFC:

Dorsolateral Prefrontal Cortex; FC: Functional Connectivity; PCC: Posterior Cingulate Cortex; LLP: Left Lateral Parietal Cortex

\begin{tabular}{|c|c|c|c|c|c|c|}
\hline $\begin{array}{l}\text { Study } \\
\#\end{array}$ & Title, Author (s), Year & $\begin{array}{l}\text { Neuroimaging } \\
\text { Method }\end{array}$ & g Sample r Size & 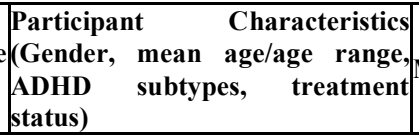 & Methylphenidate Intervention & Principle Findings \\
\hline 23 & $\begin{array}{l}\text { Effects of Methylphenidate on Default- } \\
\text { Mode Network/Task-Positive Network } \\
\text { Synchronization in Children with ADHD } \\
\text { (Querne et al., 2017) }\end{array}$ & $\begin{array}{l}\text { Task-based } \\
\text { fMRI }\end{array}$ & $\begin{array}{l}\mathrm{nADHD}=11 \\
\mathrm{nHC}=11 \\
\mathrm{nTotal}=22\end{array}$ & $\begin{array}{l}\text { ADHD: age }=9.8+/-1.7 \text { years, all } \\
\text { ADHD-C, medication naïve } \\
\text { HC: age }=10.8+/-1.7 \text { years }\end{array}$ & 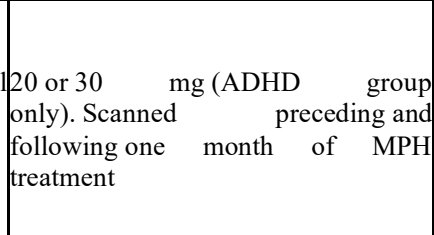 & $\begin{array}{l}\text { No significant anticorrelation between DMN and } \\
\text { TPN along with non-synchronized activity of the } \\
\text { pMN in unmedicated ADHD patients. MPH } \\
\text { dinduced } \\
\text { ind DMN synchronization and } \\
\text { a synchronized anticorrelation between the DMN } \\
\text { and TPN } \rightarrow \text { DMN suppression in ADHD } \\
\text { individuals. }\end{array}$ \\
\hline 24 & $\begin{array}{l}\text { The Effect of Methylphenidate on Very } \\
\text { Low Frequency Electroencephalography } \\
\text { Oscillations in Adult ADHD (Cooper et } \\
\text { al., 2014) }\end{array}$ & $\begin{array}{l}\text { Task- } \\
\text { based EEG }\end{array}$ & 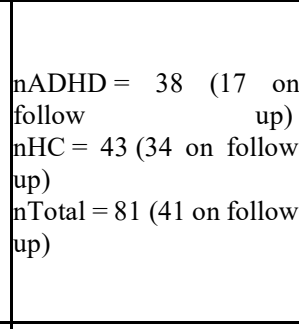 & $\begin{array}{l}\text { ADHD: All male, mean age }=28.7 \\
+/-\quad 7.7 \text { years (follow up } \\
\text { sample), minimum wash out period } \\
\text { of } 1 \text { month (19 prescribed } \\
\text { stimulants in original sample), 32 } \\
\text { ADHD-C and } 8 \text { ADHD-I in original } \\
\text { sample } \\
\text { HC: All male, mean age }=29.2+/- \\
10.4 \text { years }\end{array}$ & $\begin{array}{l}\text { Scanned before and after MPH } \\
\text { treatment with mean follow up of } 9.4 \\
\text { months (ADHD group only) }\end{array}$ & $\begin{array}{l}\text { MPH resulted in Reduced DMN activity evident by } \\
\text { a reduction of very low } \begin{array}{r}\text { frequency } \\
\text { electroencephalographic }\end{array} \\
\text { EEG) typically found in the DMN }\end{array}$ \\
\hline 25 & $\begin{array}{l}\text { Drug-Specific Laterality Effects on } \\
\text { Frontal Lobe Activation of Atomoxetine } \\
\text { and Methylphenidate in Attention } \\
\text { Deficit Hyperactivity Disorder Boys } \\
\text { During Working Memory (Cubillo et al., } \\
\text { 2014) }\end{array}$ & $\begin{array}{l}\text { Task- } \\
\text { based fMRI }\end{array}$ & $\begin{array}{l}\mathrm{nADHD}= \\
\mathrm{nHC}=20 \\
\mathrm{nTotal}=40\end{array}$ & $\begin{array}{l}\text { ADHD: All male, age }=10-17 \\
\text { years, all ADHD-C and medication } \\
\text { naïve } \\
\text { HC: All male, age }=10-17 \text { years }\end{array}$ & $\begin{array}{l}3 \text { scans in random order with single } \\
\text { dose of either MPH }(0.3 \mathrm{mg} / \mathrm{kg}, 5-20 \\
\mathrm{mg}) \text {, placebo }(50 \mathrm{mg}) \text { or ATX }(1 \\
\mathrm{mg} / \mathrm{kg}, 16-66 \mathrm{mg}) \text {. Medication free } \\
\text { between scans (ADHD group only) }\end{array}$ & $\begin{array}{l}\text { ADHD group displayed significantly reduced } \\
\text { activity in the bilateral DLPFC under } \\
\text { placebo. MPH increased right DLPFC } \\
0 \text { activity and enhanced left inferior frontal cortex } \\
1 \text { activity only during the 2-back task (2nd level out of } \\
\text { 4). MPH increased fronto-temporo-striatal } \\
\text { activation in ADHD and deactivated the DMN, } \\
\text { which were negatively correlated with the } \\
\text { decreased DLPFC activation. }\end{array}$ \\
\hline 26 & $\begin{array}{|lr|}\text { Pattern Classification of Working } \\
\text { Memory Networks Reveals Differential } \\
\text { Effects rethylphenidate, } \\
\text { Atomoxetine, and Placebo in Healthy } \\
\text { Volunteers (Marquand et al., 2011) } \\
\end{array}$ & $\begin{array}{l}\text { Task-based } \\
\text { fMRI }\end{array}$ & $\begin{array}{l}\text { nADHD }=0 \\
\text { nHC }=15 \\
\text { nTotal }=15\end{array}$ & HC: All male, age $=20-39$ years & $\begin{array}{l}30 \mathrm{mg} \text { MPH or placebo. Scanned } 90- \\
135 \text { minutes after MPH or } \\
\text { placebo administration }\end{array}$ & $\begin{array}{l}\text { MPH increased task-related deactivations in DMN } \\
\text { regions and increased activity in working memory } \\
\text { networks during reward trials }\end{array}$ \\
\hline 27 & $\begin{array}{l}\text { Task-related Default Mode Network } \\
\text { Modulation and Inhibitory Control in } \\
\text { ADHD: Effects of Motivation and } \\
\text { Methylphenidate (Liddle et al., 2011) }\end{array}$ & $\begin{array}{l}\text { Task-b } \\
\text { fMRI }\end{array}$ & $\begin{array}{l}\mathrm{nADHD}=18 \\
\mathrm{nHC}=18 \\
\mathrm{nTotal}=36\end{array}$ & $\begin{array}{l}\text { ADHD: } 17 \mathrm{M} / 1 \quad \mathrm{~F} \text {, age }=9-15 \\
\text { years }+/-6 \text { months, all ADHD- } \\
\text { C, on MPH treatment } \\
\text { HC: All male, age }=9-15 \text { years }+/- \\
6 \text { months }\end{array}$ & 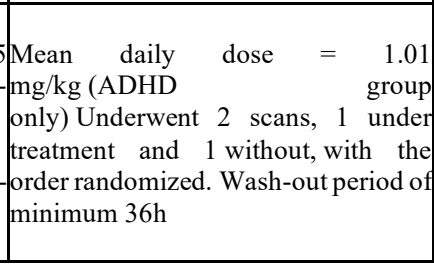 & $\begin{array}{l}\text { Unmedicated children } \\
1 \text { displayed significantly reduced } \\
\text { pMN deactivation with low incentive, but no } \\
\text { endifferences seen between HC and } \\
\text { e ADHD groups with high incentive. Task-related } \\
\text { DMN suppression seen with MPH treatment and } \\
\text { no differences seen between the HC and ADHD } \\
\text { group in either motivational states. }\end{array}$ \\
\hline
\end{tabular}




\begin{tabular}{|c|c|c|c|c|c|c|}
\hline 28 & \begin{tabular}{|lrl|} 
First-Dose & \multicolumn{2}{c|}{ Methylphenidate-Induced } \\
Changes in Brain Functional \\
Connectivity Are Correlated with 3- \\
Month Attention-Deficit/Hyperactivity \\
Disorder $\quad$ Symptom & Response \\
(Silberstein et al., 2017) & \\
\end{tabular} & $\begin{array}{l}\text { Task-based } \\
\text { EEG } \\
\end{array}$ & $\begin{array}{l}\text { nADHD }=40 \\
\text { nHC }=0 \\
\text { nTotal }=40\end{array}$ & $\begin{array}{l}\text { ADHD: All male, mean age }= \\
10.083+/-1.75 \text { years, medication } \\
\text { naïve, ADHD subtype data not } \\
\text { available }\end{array}$ & $\begin{array}{l}0.3 \mathrm{mg} / \mathrm{kg} \text { of patient weight. Scanned } \\
\text { before and } 90 \text { minutes after MPH } \\
\text { treatment }\end{array}$ & $\begin{array}{l}\text { MPH induced decrease in FC of the frontal- } \\
\text { prefrontal regions }\end{array}$ \\
\hline 29 & $\begin{array}{l}\text { Methylphenidate Alters Functional } \\
\text { Connectivity of Default Mode Network } \\
\text { in Drug-Naïve Male Adults with ADHD } \\
\text { (Picon et al., 2020) }\end{array}$ & $\begin{array}{l}\text { Resting- } \\
\text { state fMRI }\end{array}$ & $\begin{array}{l}\text { nADHD = } 18 \\
\text { nHC =0 } \\
\text { nTotal = } 18\end{array}$ & $\begin{array}{l}\text { ADHD: All male, age }=30.67+/- \\
\text { 7.41, 12 ADHD-C and } 6 \text { ADHD- } \\
\text { I, medication naïve }\end{array}$ & \begin{tabular}{|lr} 
Mean dose $=29.72 \mathrm{mg}$ daily (dose \\
increased & gradually r until \\
reaching individually specific optimal \\
level) for a mean duration of 54.44 \\
days
\end{tabular} & $\begin{array}{l}\text { Increased } \\
\text { PCC and I }\end{array}$ \\
\hline 30 & 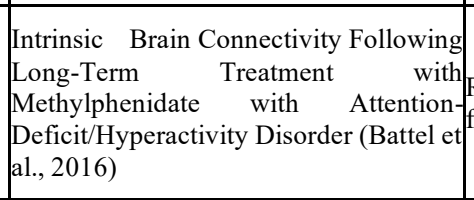 & $\begin{array}{l}\text { Resting-state } \\
\text { fMRI }\end{array}$ & 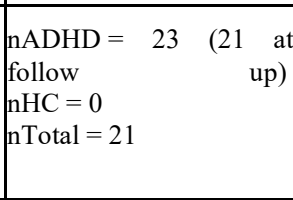 & $\begin{array}{l}\text { ADHD: All male, age }=8.78 \\
+/-0.85 \text {, medication naïve, subtype } \\
\text { data not available }\end{array}$ & $\begin{array}{l}\text { Scanned before and after } 6 \text { months of } \\
\text { MPH treatment (target dose of } 1 \\
\mathrm{mg} / \mathrm{kg} / \text { day) }\end{array}$ & $\begin{array}{l}\text { No significant difference in connectivity between } \\
\text { DMN regions, though a relatively small increase in } \\
\text { the anterior and posterior DMN. Significant } \\
\text { increase in connectivity between putamen and } \\
\text { DMN which was associated with a decrease in } \\
\text { symptoms }\end{array}$ \\
\hline
\end{tabular}




\section{Discussion}

The objective of this systematic review was to assist in the development of a neuroimagingbased diagnosis of ADHD. To do this, the functioning of the DMN and its antagonistic TPNs was examined in patients with ADHD to investigate the potential role of these networks in the pathology of ADHD. Additionally, the effects of the pharmacological treatment of methylphenidate on DMN functioning was assessed to track treatment response. Functioning of the Default Mode and Task Positive Network in Attention Deficit Hyperactivity Disorder

The DMN is active during a resting state and an altered regulation of the DMN has been linked to symptoms of ADHD (Hoekzema et al., 2014). Research has found that individuals with ADHD have altered DMN connectivity which is associated with expressed symptoms of ADHD (Pironti et al., 2019). Since individuals with ADHD display a hyperactive DMN (Norman et al., 2017), it was hypothesized that one of the characteristics of ADHD is a hyperconnected DMN. Although mixed results of the present systematic review, more studies opposed this hypothesis and demonstrated that patients with ADHD have reduced functional connectivity of the DMN. The reduced functional connectivity of the DMN is thought to most likely be due to the DMN being less integrated (Tao et al., 2017) and may serve as a dimensional neuropathophysiological endophenotype of the disorder (Pironti et al., 2019) A second hypothesis of ADHD proposed was that the hyperactivity of the DMN results in underactivity of the TPN. In other words, there is a reduced anticorrelation between the DMN and TPN. ADHD symptoms are hypothesized to be caused by the intrusion of DMN activity over the TPN (Picon et al., 2018). As such, altered neural activity is not confined to DMN intrusion during tasks, but also insufficient suppression of task positive regions such as the DLPFC during 
rest (Hoekzema et al., 2014). Majority of studies demonstrated that ADHD is linked to reduced anticorrelation between the DMN and TPN with only one study finding increased anticorrelation between the DMN and TPN and one study finding no difference in anticorrelation between ADHD patients and healthy controls. The reduced anticorrelation between the TPN and DMN also confirms that ADHD patients display a reduced suppression of the DMN (Oldehinkel et al., 2016). This may be explained by increased connectivity from the primary sensory cortex to DMN regions which suggest altered information flow from sensory to cognitive regions with increased information flow to the DMN instead of the frontoparietal executive system, consistent with the DMN interference hypothesis (Carmona et al., 2015). Therefore, it can be hypothesized that an inability to deactivate the DMN while performing tasks may result in thought intrusions and interruptions in processing of the TPN (Querne et al., 2017). In addition, healthy brain function is associated with a strong anticorrelation between the DMN and TPN (Abbas et al., 2019), demonstrating that the reduced anticorrelation between the two networks may be a pathology that can be used as an additional component for the diagnosis of ADHD.

It was also hypothesized that reduced anticorrelation between the DMN and TPN is linked to increased connectivity between those networks. Again, mixed findings were obtained in which half the studies indicated that DMN and TPN are hyperconnected with one study indicating reduced connectivity, one study indicating mixed findings, and one study with findings of no difference in connectivity between the two networks in patients with ADHD compared to healthy controls. This dysfunctional connectivity between the TPN and DMN is most likely due to altered switching of the brain from a resting to a functional state, resulting in periodic lapses on task performance which is a hallmark of ADHD (Kyeong et al., 
2017). This connectivity pattern is also linked to higher ADHD symptoms mediated by performance on attention-related tasks (Pironti et al., 2019).

The overall goal of this systematic review was to assess if the DMN function is altered in ADHD patients. Seven studies used various measures to assess the function of the DMN in individuals with ADHD whose findings show that the DMN functions differently in these individuals. In particular, the enhanced temporal variability of the DMN in ADHD patients suggests altered synchronization of the DMN and associated task positive regions which again suggests reduced anticorrelation between the PCC and task positive regions (Zhang et al., 2018). Similarly, the enhanced temporal activity seen in DMN-associated internal control networks (ICNs) may be due to a disruption in functional interactions within the DMN (Wang \& $\mathrm{Li}, 2015)$. The brain signal variability of the DMN seen in ADHD patients also points towards disrupted activity between the DMN and TPN, the CEN in particular (Nomi et al., 2018). Furthermore, the strong coherence between TPN regions such as the DLPFC and $\mathrm{dACC}$ with DMN regions suggest higher connectivity strength between the two networks which favours the above findings (Kumar et al., 2020).

Homogeneity is also a measure of cohesiveness which was found to be reduced in the DMN of ADHD patients (Uddin et al., 2008). Other research has also reported reduced homogeneity of DMN regions which is consistent with the DMN interference hypothesis as a major contributor to the inattentive symptoms of ADHD (Uddin et al., 2008). The reduced homogeneity may be due to reduced functional interactions between DMN regions such as the precuneus and cognitive control regions such as the anterior cingulate which result in deficits in executive function, which is also a characteristic of ADHD (Uddin et al., 2008). 
The findings of this systematic review indicate that patients with ADHD have altered functioning of the DMN in comparison to healthy controls, supporting the DMN interference hypothesis, and suggesting that the DMN is involved in producing symptoms of ADHD (Silberstein et al., 2017).

\section{Effects of Methylphenidate on the Default Mode Network}

Research regarding the DMN has allowed researchers to examine the effects of medications such as methylphenidate on the DMN in ADHD individuals. Methylphenidate stimulant medication has been the primary form of treatment for ADHD (Kaboodvand et al., 2020). We see that methylphenidate influences the DMN (Picon et al., 2018), and since the DMN is impaired in ADHD, one can predict that it may 'normalize' DMN functioning in patients with ADHD, which was supported by present findings. All studies that investigated DMN activity showed that methylphenidate results in DMN suppression. This is a therapeutic response since individuals with ADHD display a hyperactive DMN (Norman et al., 2017). In addition, since it was hypothesized that ADHD patients have enhanced connectivity of the DMN, it was also hypothesized that methylphenidate will cause a reduction in DMN connectivity. However, in opposition to these hypotheses, more research illustrated reduced functional connectivity within the DMN in patients with ADHD. Therefore, it can be speculated that methylphenidate will increase functional connectivity within the DMN. One study did confirm this (Picon et al., 2020) with another study showing that there is a slight but not a significant increase in connectivity of the anterior and posterior DMN (Battel et al., 2016). Furthermore, it was found that methylphenidate reduced functional connectivity of the frontal-prefrontal regions (Silberstein et al., 2017) which would have been predicted since methylphenidate increases functional connectivity of the DMN. 
The dopamine hypothesis proposes that ADHD symptoms are expressed due to deficits in dopamine (Genro et al., 2010). This hypothesis is supported by findings of this systematic review since the studies demonstrate that methylphenidate results in therapeutic effects by enhancing dopamine and norepinephrine levels (Silberstein et al., 2017), treating the dopamine aspect of ADHD. In addition, recent evidence has found that dopamine is also linked to functioning of the DMN (Silberstein et al., 2016). Since methylphenidate has therapeutic effects by enhancing dopamine (Silberstein et al., 2017), it should also have an impact on the DMN which is impaired in ADHD as shown in this systematic review. As predicted, we see that methylphenidate has therapeutic effects by enhancing dopamine which in turn suppresses networks such as the DMN that interfere with task performance (Silberstein et al., 2017).

These findings demonstrate that methylphenidate may have positive effects by increasing dopamine and norepinephrine, which suppress the functional connectivity of networks that disturb task performance such as the DMN among others (Silberstein et al., 2017). In addition, stimulant medications elevate anticorrelation between cognitive control networks and the DMN while performing tasks (Barber et al., 2015), which would be therapeutic since majority of studies in this systematic review showed that patients with ADHD have a reduced anticorrelation between the DMN and TPN. Furthermore, research has shown that neural connections within the DMN becomes stronger with age in healthy individuals, which may suggest that methylphenidate induced increase in functional connectivity within the DMN may aid in the maturing of the DMN, allowing an improvement of symptoms (Picon et al., 2020). Therefore, it can be hypothesized that stronger functional connectivity within the DMN induced by methylphenidate treatment can be a means to improve DMN function which could alleviate ADHD symptoms (Picon et al., 2018). In addition, since stimulants have shown 
to modulate activation strength and normalize impaired connectivity, it can be concluded that ADHD may be a disorder of network dysfunction (Konrad \& Eivkoff, 2010).

\section{Limitations and Future Directions}

Although there were strong findings of a reduced anticorrelation between the DMN and TPN and methylphenidate induced suppression of the DMN in patients with ADHD, there were inconclusive or mixed findings regarding the functional connectivity within the DMN and between the DMN and TPN. The inconsistency in findings may be due to ADHD in general being a disorder which is difficult to study due to its high comorbidity with other disorders (Belanger et al., 2018). However, to account for this factor, the studies did develop their inclusion/exclusion criteria accordingly in which the primary diagnosis of the participants had to be ADHD, though even with strict inclusion and exclusion criteria, it is very difficult to isolate ADHD due to it being a highly heterogeneous disorder (Luo et al., 2019). As neuroconnectivity in ADHD patients were compared to healthy controls in the studies of this systematic review, it is also possible that some of the reported differences in DMN connectivity could be mediated by associated co-morbidities for some of the patients, contributing to the heterogeneity of the results.

The inconsistency in findings between studies may also be due to the variability in the ADHD subtypes used in samples of some studies. Despite clinical and behavioural differences between ADHD subtypes, a high level of ADHD research does not distinguish between these groups and directly compare a heterogeneous ADHD group with a non-ADHD group (Mohan et al., 2016). As seen here, not all studies kept uniform samples of using one subtype of ADHD. This would cause a variability in findings between studies as brain organization does appear to differ between ADHD subtypes (Saad et al., 2017). Treatment status 
of participants within the ADHD sample was also not accounted for in all studies. This is an important factor as despite a washout period, the effects of prolonged use of stimulant medications may have long lasting effects on network integrity and task performance (Barber et al., 2015). Additionally, there were studies that used secondary neuroimaging data which is susceptible to bias and reduced reliability in comparison to primary data due to less control of the methodology involved in data collection. Given that several of these studies depended on the same source neuroimaging dataset, this could also cause disproportionate emphasis on specific experimental results in terms of inflating $\mathrm{n}$ values and the associated results from one specific study.

In addition to limitations of current research in this area, there were also limitations associated with this systematic review. Although the studies themselves accounted for gender and age, the present systematic review did not control for age and gender, which is an important limitation since DMN activity in ADHD is affected by gender and age (Dumais et al., 2018; Park et al., 2016). There was also no control for the sample size which affects the level of significance, power and effect size of studies (Bhalerao \& Kadam, 2010). In addition, control for ADHD subtype, treatment, use of primary versus secondary data, and inclusion/exclusion criteria of studies were also not considered due to such constraints resulting in a low yield of studies for a systematic review in this only recently emerging field of study. To account for this, the inclusion criteria was broadened, and exclusion criteria narrowed. Another limitation of the present systematic review is that one investigator carried out the systematic review which tends to produce a selection and analysis bias, affecting the reliability and reproducibility of results.

Nevertheless, the majority of research in this systematic review did point towards an impaired DMN in ADHD, supporting the DMN interference hypothesis. The second part of the 
systematic review had stronger and consistent findings which again supports the dopamine hypothesis of ADHD. Future research should focus on building evidence behind an impaired DMN in ADHD, by making use of more uniform samples that consider the aforementioned limitations, as it may assist in developing a neuroimaging-based diagnosis of ADHD.

\section{Conclusion}

The goal of this systematic review was to assist in the development of a neuroimaging-based diagnosis of ADHD by examining the functioning of the DMN and its relative activity with the TPN, and to assess if methylphenidate treatment can 'normalize' the functioning of the DMN in ADHD. The results of this systematic review support that ADHD is a disorder of DMN dysfunction and dopamine alterations which can be treated by methylphenidate, again supporting the DMN interference and dopamine hypothesis. The present research may assist in a more accurate diagnosis of ADHD and may provide a potential target for future treatments and interventions.

\section{Funding}

There was no funding provided to conduct the present systematic review. 


\section{References}

Abbas, A., Basal, Y., \& Keilholz, S. (2019). Quasi-periodic patterns of brain activity in individuals with attention-deficit/hyperactivity disorder. NeuroImage: Clinical, 21. DOI: 10.1016/j.nicl.2019.101653

Aboitiz, F., Ossandón, T., Zamorano, F., Palma, B., \& Carrasco, X. (2014). Irrelevant stimulus processing in ADHD: Catecholamine dynamics and attentional networks. Frontiers in Psychology, 5(183). DOI: 10.3389/fpsyg.2014.00183

Adesman, A. R. (2001). The diagnosis and management of attention-deficit/hyperactivity disorder in pediatric patients. Primary Care Companion to the Journal of Clinical Psychiatry, 3(2), 6677. DOI: $10.4088 /$ pcc.v03n0204

Anita, T \& Stergiakouli, E. (2009). An Overview on the Genetics of ADHD. Acta Psychologica Sinica, 40(10), 1088-1098. DOI: 10.3724/SP.J.1041.2008.01088

Bahçıvan Saydam, R., Belgin Ayvaşik, H., \& Alyanak, B. (2015). Executive functioning in subtypes of attention deficit hyperactivity disorder. Noropsikiyatri Arsivi-Archives of Neuropsychiatry, 52(4), 386-392. DOI: 10.5152/npa.2015.8712

Barber, A. D., Jacobson, L. A., Wexler, J. L., Nebel, M. B., Caffo, B. S., Pekar, J. J., \& Mostofsky, S. H. (2015). Connectivity supporting attention in children with attention deficit hyperactivity disorder. NeuroImage: Clinical, 7, 68-81. DOI: 10.1016/j.nicl.2014.11.011

Baroni, A., \& Castellanos, F. X. (2015). Neuroanatomic and cognitive abnormalities in attentiondeficit/hyperactivity disorder in the era of "high definition" neuroimaging. Current Opinion in Neurobiology, 0, 1-8, . DOI: 10.1016/j.conb.2014.08.005 
Battel, L., Kieling, R. R., Kieling, C., Anés, M., Aurich, N. K., Da Costa, J. C., ... Franco, A. R. (2016). Intrinsic Brain Connectivity Following Long-Term Treatment with Methylphenidate in Children with Attention-Deficit/Hyperactivity Disorder. Journal of Child and Adolescent Psychopharmacology, 26(6), 555-561. DOI: 10.1089/cap.2015.0221

Bélanger, S. A., Andrews, D., Gray, C., \& Korczak, D. (2018). ADHD in children and youth: Part 1 Etiology, diagnosis, and comorbidity. Pediatrics and Child Health (Canada), 23(7), 447453. DOI: $10.1093 / \mathrm{pch} / \mathrm{pxy} 109$

Bhalerao, S., \& Kadam, P. (2010). Sample size calculation. International Journal of Ayurveda Research, 1(1), 55. https://doi.org/10.4103/0974-7788.59946

Biederman, J., Kwon, A., Aleardi, M., Chouinard, V. A., Marino, T., Cole, H., ... Faraone, S. V. (2005). Absence of gender effects on attention deficit hyperactivity disorder: Findings in nonreferred subjects. American Journal of Psychiatry, 162(6), 1083-1089. DOI: 10.1176/appi.ajp.162.6.1083.

Biswal, B., Zerrin Yetkin, F., Haughton, V. M., \& Hyde, J. S. (1995). Functional connectivity in the motor cortex of resting human brain using echo-planar MRI. Magnetic Resonance in Medicine, 34(4), 537-541. DOI: 10.1002/mrm.1910340409

Bos, D. J., Oranje, B., Achterberg, M., Vlaskamp, C., Ambrosino, S., de Reus, M. A., ... Durston, S. (2017). Structural and functional connectivity in children and adolescents with and without attention deficit/hyperactivity disorder. Journal of Child Psychology and Psychiatry and Allied Disciplines, 58(7), 810-818. DOI: 10.1111/jcpp.12712 
Broyd, S. J., Demanuele, C., Debener, S., Helps, S. K., James, C. J., \& Sonuga-Barke, E. J. S. (2009). Default-mode brain dysfunction in mental disorders: A systematic review. Neuroscience and Biobehavioral Reviews, 33(3), 279-96. DOI: 10.1016/j.neubiorev.2008.09.002.

Buckner, R. L., Andrews-Hanna, J. R., \& Schacter, D. L. (2008, March). The brain's default network: Anatomy, function, and relevance to disease. Annals of the New York Academy of Sciences, 1124, 1-38. DOI: 10.1196/annals.1440.011

Bulgarelli, C., Blasi, A., de Klerk, C. C. J. M., Richards, J. E., Hamilton, A., \& Southgate, V. (2019). Fronto-temporoparietal connectivity and self-awareness in 18-month-olds: A resting state fNIRS study. Developmental Cognitive Neuroscience, 38: 100676. DOI: 10.1016/j.dcn.2019.100676.

Bulgarelli, C., de Klerk, C. C. J. M., Richards, J. E., Southgate, V., Hamilton, A., \& Blasi, A. (2020). The developmental trajectory of fronto-temporoparietal connectivity as a proxy of the default mode network: a longitudinal fNIRS investigation. Human Brain Mapping, 41(10), 2717-2740. DOI: $10.1002 / \mathrm{hbm} .24974$.

Cai, W., Chen, T., Szegletes, L., Supekar, K., \& Menon, V. (2018). Aberrant Time-Varying CrossNetwork Interactions in Children With Attention-Deficit/Hyperactivity Disorder and the Relation to Attention Deficits. Biological Psychiatry: Cognitive Neuroscience and Neuroimaging, 3(3), 263-273. DOI: 10.1016/j.bpsc.2017.10.005

Cao, W., Luo, C., Zhu, B., Zhang, D., Dong, L., Gong, J., ... Yao, D. (2014). Resting-state functional connectivity in anterior cingulate cortex in normal aging. Frontiers in Aging Neuroscience, 6(280). DOI: 10.3389/fnagi.2014.00280. 
Carmona, S., Hoekzema, E., Castellanos, F. X., García-García, D., Lage-Castellanos, A., Van Dijk, K. R. A., ... Sepulcre, J. (2015). Sensation-to-cognition cortical streams in attentiondeficit/hyperactivity disorder. Human Brain Mapping, 36(7), 2544-2557. DOI:

\subsection{2/hbm.22790}

Castellanos, F. X., Margulies, D. S., Kelly, C., Uddin, L. Q., Ghaffari, M., Kirsch, A., ... Milham, M. P. (2008). Cingulate-Precuneus Interactions: A New Locus of Dysfunction in Adult AttentionDeficit/Hyperactivity Disorder. Biological Psychiatry, 63(3), 332-337. DOI:

10.1016/j.biopsych.2007.06.025

Chand, G. B., Wu, J., Hajjar, I., \& Qiu, D. (2017). Interactions of the Salience Network and Its Subsystems with the Default-Mode and the Central-Executive Networks in Normal Aging and Mild Cognitive Impairment. Brain Connectivity, 7(7), 401-412. DOI: 10.1089/brain.2017.0509.

Chen, G., Chen, G., Xie, C., \& Li, S. J. (2011). Negative Functional Connectivity and Its Dependence on the Shortest Path Length of Positive Network in the Resting-State Human Brain. Brain Connectivity, 1(3), 195-206. DOI: 10.1089/brain.2011.0025

Chen, M. H., Chen, Y. L., Bai, Y. M., Huang, K. L., Wu, H. J., Hsu, J. W., ... Wu, Y. Te. (2020). Functional connectivity of specific brain networks related to social and communication dysfunction in adolescents with attention-deficit hyperactivity disorder. Psychiatry Research, 284. DOI: 10.1016/j.psychres.2020.112785

Childress, A. C. (2015, December 23). A critical appraisal of atomoxetine in the management of ADHD. Therapeutics and Clinical Risk Management, 12, 27-39. DOI: 10.2147/TCRM.S59270

Cooper, R. E., Skirrow, C., Tye, C., McLoughlin, G., Rijsdijk, F., Banaschweski, T., ... Asherson, P. (2014). The effect of methylphenidate on very low frequency electroencephalography 
oscillations in adult ADHD. Brain and Cognition, 86(1), 82-89. DOI:

10.1016/j.bandc.2014.02.001

Cubillo, A., Smith, A. B., Barrett, N., Giampietro, V., Brammer, M., Simmons, A., \& Rubia, K. (2014). Drug-specific laterality effects on frontal lobe activation of atomoxetine and methylphenidate in attention deficit hyperactivity disorder boys during working memory. Psychological Medicine, 44(3), 633-646. DOI: 10.1017/S0033291713000676

Curatolo, P., D’Agati, E., \& Moavero, R. (2010). The neurobiological basis of ADHD. Italian Journal of Pediatrics, 36(1), 79. DOI: 10.1186/1824-7288-36-79

Daneshparvar, M., Mostafavi, S. A., Jeddi, M. Z., Yunesian, M., Mesdaghinia, A., Mahvi, A. H., \& Akhondzadeh, S. (2016). The role of lead exposure on Attention-Deficit/Hyperactivity Disorder in children: A systematic review. Iranian Journal of Psychiatry, 11(1), 1-14.

Daniels, J. K., Mcfarlane, A. C., Bluhm, R. L., Moores, K. A., Clark, ; C Richard, Shaw, M. E., ... Daniels, P. (2010). Switching between executive and default mode networks in posttraumatic stress disorder: alterations in functional connectivity. Journal of Psychiatry \& Neuroscience, 35(4), 258-266. doi: 10.1503/jpn.090175

Di, X., \& Biswal, B. B. (2014). Modulatory interactions between the default mode network and task positive networks in resting-state. PeerJ. DOI: $10.7717 /$ peerj.367

Dumais, K. M., Chernyak, S., Nickerson, L. D., \& Janes, A. C. (2018). Sex differences in default mode and dorsal attention network engagement. PLOS ONE, 13(6). DOI: 10.1371/journal.pone.0199049 
Enriquez-Geppert, S., Smit, D., Pimenta, M. G., \& Arns, M. (2019). Neurofeedback as a Treatment Intervention in ADHD: Current Evidence and Practice. Current Psychiatry Reports, 21(6), 46. DOI: $10.1007 / \mathrm{s} 11920-019-1021-4$

Epstein, J. N., \& Loren, R. E. A. (2013). Changes in the definition of ADHD in DSM-5: Subtle but important. Neuropsychiatry. NIH Public Access.

Faraone, S. V., \& Larsson, H. (2019). Genetics of attention deficit hyperactivity disorder. Molecular Psychiatry. DOI: 10.1016/j.chc.2007.11.011

Fayyad, J., Sampson, N. A., Hwang, I., Adamowski, T., Aguilar-Gaxiola, S., Al-Hamzawi, A., ... Wojtyniak, B. (2017). The descriptive epidemiology of DSM-IV Adult ADHD in the World Health Organization World Mental Health Surveys. Attention Deficit and Hyperactivity Disorders, 9(1), 47-65. DOI: 10.1007/s12402-016-0208-3

Franke, B., Faraone, S. V., Asherson, P., Buitelaar, J., Bau, C. H. D., Ramos-Quiroga, J. A., ... Reif, A. (2012). The genetics of attention deficit/hyperactivity disorder in adults, a review. Molecular Psychiatry, 17(10), 960-87. DOI: 10.1038/mp.2011.138

Froehlich, T. E., Anixt, J. S., Loe, I. M., Chirdkiatgumchai, V., Kuan, L., \& Gilman, R. C. (2011). Update on environmental risk factors for attention-deficit/hyperactivity disorder. Current Psychiatry Reports, 13(5), 333-344. DOI: 10.1007/s11920-011-0221-3

Gao, W., Zhu, H., Giovanello, K. S., Smith, J. K., Shen, D., Gilmore, J. H., \& Lin, W. (2009). Evidence on the emergence of the brain's default network from 2-week-old to 2-year-old healthy pediatric subjects. Proceedings of the National Academy of the United States of America, 106(16), 6790-5. doi: 10.1073/pnas.0811221106. 
Gaub, M., \& Carlson, C. L. (1997). Gender differences in ADHD: A meta-analysis and critical review. Journal of the American Academy of Child and Adolescent Psychiatry, 36(8), 10361045. DOI: 10.1097/00004583-199708000-00011

Gehricke, J. G., Kruggel, F., Thampipop, T., Alejo, S. D., Tatos, E., Fallon, J., \& Muftuler, L. T. (2017). The brain anatomy of attention-deficit/hyperactivity disorder in young adults - A magnetic resonance imaging study. Clinical Trial, 12(4). DOI: 10.1371/journal.pone.0175433

Genro, J. P., Kieling, C., Rohde, L. A., \& Hutz, M. H. (2010, April). Attention-deficit/hyperactivity disorder and the dopaminergic hypotheses. Expert Review of Neurotherapeutics, 10(4), 587-601. doi: $10.1586 /$ ern.10.17.

Gerrits, B., Vollebregt, M. A., Olbrich, S., van Dijk, H., Palmer, D., Gordon, E., ... Arns, M. (2019). Probing the "Default Network Interference Hypothesis" With EEG: An RDoC Approach Focused on Attention. Clinical EEG and Neuroscience, 50(6), 404412. DOI: $10.1177 / 1550059419864461$

Gracia-Tabuenca, Z., Díaz-Patiño, J. C., Arelio, I., \& Alcauter, S. (2020). Topological data analysis reveals robust alterations in the whole-brain and frontal lobe functional connectomes in attention-deficit/ hyperactivity disorder. ENeuro, 7(3). DOI: 10.1523/ENEURO.0543-19.2020

Grimm, O., Kittel-Schneider, S., \& Reif, A. (2018, September 1). Recent developments in the genetics of attention-deficit hyperactivity disorder. Psychiatry and Clinical Neurosciences, 72(9), 654672. DOI: $10.1111 / \mathrm{pcn} .12673$ 
Hasson, U., Nusbaum, H. C., \& Small, S. L. (2009). Task-dependent organization of brain regions active during rest. Proceedings of the National Academy of Sciences of the United States of America, 106(26), 10841-6. doi: 10.1073/pnas.0903253106.

Hayashi, T. (2011). Functional Connectivity Analysis of the Brain Network Using Resting-State fMRI. Brain and Nerve, 63(12), 1307-18.

Hayashi, W., \& Iwanami, A. (2018). Biological Mechanisms of ADHD. Brain and Nerve Shinkei Kenkyu No Shinpo, 70(11), 1265-1277. DOI: 10.11477/mf.1416201172

Hayman, V., \& Fernandez, T. V. (2018). Genetic insights into ADHD biology. Frontiers in Psychiatry, 9(251). https://doi.org/10.3389/fpsyt.2018.00251

Heine, L., Soddu, A., Gómez, F., Vanhaudenhuyse, A., Tshibanda, L., Thonnard, M., ... Demertzi, A. (2012). Resting State Networks and Conciousness, Alterations of Multiple Resting State Connectivtiy in Physiological, Pharmacological, and Pathological Conscious States. Frontiers in Psychology, 3(295). DOI: 10.3389/fpsyg.2012.00295

Hilger, K., \& Fiebach, C. J. (2019). ADHD symptoms are associated with the modular structure of intrinsic brain networks in a representative sample of healthy adults. Network Neuroscience, 3(2), 567-588. DOI: 10.1162/netn_a_00083

Hoekzema, E., Carmona, S., Ramos-Quiroga, J. A., Richarte Fernández, V., Bosch, R., Soliva, J. C., ... Vilarroya, O. (2014). An independent components and functional connectivity analysis of resting state FMRI data points to neural network dysregulation in adult ADHD. Human Brain Mapping, 35(4), 1261-1272. DOI: 10.1002/hbm.22250 
Jewett, B.E., Sharma, S. (2020). Physiology, GABA.

Joanna Briggs Institute (2017). The Joanna Briggs Institute Critical Appraisal Tools for Use in JBI Systematic Reviews: Checklist for Case Control Studies. http://joannabriggs.org/research/criticalappraisal-tools.html

Joshi, G., Arnold Anteraper, S., Patil, K. R., Semwal, M., Goldin, R. L., Furtak, S. L., ... WhitfieldGabrieli, S. (2017). Integration and Segregation of Default Mode Network Resting-State Functional Connectivity in Trasition-Age Males with High-Functioning Autism Spectrum Disorder: A Proof-of-Concept Study. Brain Connectivity, 7(9), 558-573. DOI:

\subsection{9/brain.2016.0483.}

Juárez Olguín, H., Calderón Guzmán, D., Hernández García, E., \& Barragán Mejía, G. (2016). The role of dopamine and its dysfunction as a consequence of oxidative stress. Oxidative Medicine and Cellular Longevity, 2016(9730467). DOI: 10.1155/2016/9730467

Kaboodvand, N., Iravani, B., \& Fransson, P. (2020). Dynamic synergetic configurations of resting-state networks in ADHD. NeuroImage, 207, 116347. DOI: 10.1016/j.neuroimage.2019.116347

Konrad, K., \& Eickhoff, S. B. (2010, June). Is the ADHD brain wired differently? A review on structural and functional connectivity in attention deficit hyperactivity disorder. Human Brain Mapping, 31(6), 904-16. DOI: 10.1002/hbm.21058.

Krain, A. L., \& Castellanos, F. X. (2006). Brain development and ADHD. Clinical Psychology Review, 26(4), 433-444. DOI: 10.1016/j.cpr.2006.01.005 
Kumar, U., Arya, A., \& Agarwal, V. (2020). Neural network connectivity in ADHD children: an independent component and functional connectivity analysis of resting state fMRI data. Brain Imaging and Behavior, 15, 157-165. DOI: 10.1007/s11682-019-00242-0

Kyeong, S., Kim, J. J., \& Kim, E. (2017). Novel subgroups of attention-deficit/hyperactivity disorder identified by topological data analysis and their functional network modular organizations. PLoS ONE, 12(8). DOI: 10.1371/journal.pone.0182603

Lee, M. H., Smyser, C. D., \& Shimony, J. S. (2013). Resting-state fMRI: A review of methods and clinical applications. American Journal of Neuroradiology, 34(10), 1866-1872. DOI: 10.3174/ajnr.A3263

Liddle, E. B., Hollis, C., Batty, M. J., Groom, M. J., Totman, J. J., Liotti, M., ... Liddle, P. F. (2011). Task-related default mode network modulation and inhibitory control in ADHD: Effects of motivation and methylphenidate. Journal of Child Psychology and Psychiatry and Allied Disciplines, 52(7), 761-771. DOI: 10.1111/j.1469-7610.2010.02333.x

Lin, H., Lin, Q., Li, H., Wang, M., Chen, H., Liang, Y., ... Huang, X. (2018). Functional Connectivity of Attention-Related Networks in Drug-Naïve Children With ADHD. Journal of Attention Disorders, 25(3), 377-388. DOI: 10.1177/1087054718802017

Luo, Y., Weibman, D., Halperin, J. M., \& Li, X. (2019). A review of heterogeneity in attention deficit/hyperactivity disorder (ADHD). Frontiers in Human Neuroscience, 13(42). DOI: 10.3389/fnhum.2019.00042

Mak, L. E., Minuzzi, L., MacQueen, G., Hall, G., Kennedy, S. H., \& Milev, R. (2017). The Default Mode Network in Healthy Individuals: A Systematic Review and Meta-Analysis. Brain Connectivity, 7(1), 25-33. DOI: 10.1089/brain.2016.0438 
Marquand, A. F., De Simoni, S., O’Daly, O. G., Williams, S. C. R., Mouro-Miranda, J., \& Mehta, M. A. (2011). Pattern classification of working memory networks reveals differential effects of methylphenidate, atomoxetine, and placebo in healthy volunteers. Neuropsychopharmacology, 36(6), 1237-1247. DOI: 10.1038/npp.2011.9

Mills, B. D., Miranda-Dominguez, O., Mills, K. L., Earl, E., Cordova, M., Painter, J., ... Fair, D. A. (2018). ADHD and attentional control: Impaired segregation of task positive and task negative brain networks. Network Neuroscience, 2(2), 200-217. DOI: 10.1162/netn_a_00034

Mohan, A., Roberto, A.J., Mohan, A., Lorenzo A., Jones, K., Carney M.J.,..,Lapidus, K.A.B. (2016). The Significance of the Default Mode Network (DMN) in Neurological and Neuropsychiatric Disorders: A Review. The Yale Journal of Biology and Medicine, 89(1), 49-57.

Mowinckel, A. M., Alnæs, D., Pedersen, M. L., Ziegler, S., Fredriksen, M., Kaufmann, T., ... Biele, G. (2017). Increased default-mode variability is related to reduced task-performance and is evident in adults with ADHD. NeuroImage: Clinical, 16, 369-382. DOI: 10.1016/j.nicl.2017.03.008

Nikolas, M. A., \& Nigg, J. T. (2013). Neuropsychological performance and attention-deficit hyperactivity disorder subtypes and symptom dimensions. Neuropsychology, 27(1), 107120. DOI: $10.1037 / \mathrm{a} 0030685$

Nomi, J. S., Schettini, E., Voorhies, W., Bolt, T. S., Heller, A. S., \& Uddin, L. Q. (2018). Resting-state brain signal variability in prefrontal cortex is associated with ADHD symptom severity in children. Frontiers in Human Neuroscience, 12 (90). DOI: 10.3389/fnhum.2018.00090 
Norman, L. J., Carlisi, C. O., Christakou, A., Cubillo, A., Murphy, C. M., Chantiluke, K., ... Rubia, K. (2017). Shared and disorder-specific task-positive and default mode network dysfunctions during sustained attention in paediatric Attention-Deficit/Hyperactivity Disorder and obsessive/compulsive disorder. NeuroImage: Clinical, 15, 181193. DOI: $10.1016 /$ j.nicl.2017.04.013

Oldehinkel, M., Beckmann, C. F., Franke, B., Hartman, C. A., Hoekstra, P. J., Oosterlaan, J., ... Mennes, M. (2016). Functional connectivity in cortico-subcortical brain networks underlying reward processing in attention-deficit/hyperactivity disorder. NeuroImage Clinical, 12, 796805. DOI: $10.1016 /$ j.nicl.2016.10.006

Park, B. Y., Kim, J., \& Park, H. (2016). Differences in connectivity patterns between child and adolescent attention deficit hyperactivity disorder patients. In Proceedings of the Annual International Conference of the IEEE Engineering in Medicine and Biology Society, EMBS, Annual International Conference, 2016, 1127-1130. DOI: 10.1109/EMBC.2016.7590902

Picon, F. A., Sato, J. R., Anés, M., Vedolin, L. M., Mazzola, A. A., Valentini, B. B., ... Rohde, L. A. P. (2020). Methylphenidate Alters Functional Connectivity of Default Mode Network in DrugNaive Male Adults With ADHD. Journal of Attention Disorders, 24(3), 447455. DOI: $10.1177 / 1087054718816822$

Pironti, V. A., Vatansever, D., \& Sahakian, B. J. (2019). Shared alterations in resting-state brain connectivity in adults with attention-deficit/hyperactivity disorder and their unaffected firstdegree relatives. Psychological Medicine, 1-11. DOI: 10.1017/S0033291719003374 
PLoS Medicine (OPEN ACCESS) Moher D, Liberati A, Tetzlaff J, Altman DG, The PRISMA Group (2009). Preferred Reporting Items for Systematic Reviews and Meta-Analyses: The PRISMA Statement. PLoS Med 6(7): e1000097. doi:10.1371/journal.pmed1000097

Proal, E., Reiss, P. T., Klein, R. G., Mannuzza, S., Gotimer, K., Ramos-Olazagasti, M. A., ... Castellanos, F. X. (2011). Brain Gray matter Deficits at 33-year Follow-Up in Adults with Attention-Deficit/Hyperactivity Disorder. Arch Gen Psychiatry, 68(11), 1122-1134.

DOI: 10.1001/archgenpsychiatry.2011.117

Qiu, M. G., Ye, Z., Li, Q. Y., Liu, G. J., Xie, B., \& Wang, J. (2011). Changes of Brain structure and function in ADHD children. Brain Topography, 24(3-4), 243-252. DOI: 10.1007/s10548-010$0168-4$

Querne, L., Fall, S., Le Moing, A. G., Bourel-Ponchel, E., Delignières, A., Simonnot, A., ... Berquin, P. (2017). Effects of Methylphenidate on Default-Mode Network/Task-Positive Network Synchronization in Children With ADHD. Journal of Attention Disorders, 21(14), 12081220. DOI: $10.1177 / 1087054713517542$

Raichle, M. E. (2015). The Brain's Default Mode Network. Annual Review of Neuroscience, 38, 433447. DOI: 10.1146/annurev-neuro-071013-014030

Roselló, B., Berenguer, C., Baixauli, I., Mira, Á., Martinez-Raga, J., \& Miranda, A. (2020). Empirical examination of executive functioning, ADHD associated behaviors, and functional impairments in adults with persistent ADHD, remittent ADHD, and without ADHD. BMC Psychiatry, 20(1), 134. DOI: $10.1186 / s 12888-020-02542-y$ 
Saad, J. F., Griffiths, K. R., Kohn, M. R., Clarke, S., Williams, L. M., \& Korgaonkar, M. S. (2017). Regional brain network organization distinguishes the combined and inattentive subtypes of Attention Deficit Hyperactivity Disorder. NeuroImage: Clinical, 15, 383-

390. DOI: 10.1016/j.nicl.2017.05.016

Salvi, V., Migliarese, G., Venturi, V., Rossi, F., Torriero, S., Viganò, V., ... Mencacci, C. (2019). ADHD in adults: Clinical subtypes and associated characteristics. Rivista Di Psichiatria, 54(2), 84-89. DOI: $10.1708 / 3142.31249$

Sharma, A., \& Couture, J. (2014, February). A Review of the Pathophysiology, Etiology, and Treatment of Attention-Deficit Hyperactivity Disorder (ADHD). Annals of Pharmacotherapy, 48(2), 209225. DOI: $10.1177 / 1060028013510699$

Silberstein, R. B., Levy, F., Pipingas, A., \& Farrow, M. (2017). First-Dose Methylphenidate-Induced Changes in Brain Functional Connectivity Are Correlated With 3-Month AttentionDeficit/Hyperactivity Disorder Symptom Response. Biological Psychiatry, 82(9), 679686. DOI: 10.1016/j.biopsych.2017.03.022

Silberstein, R. B., Pipingas, A., Farrow, M., Levy, F., \& Stough, C. K. (2016). Dopaminergic modulation of default mode network brain functional connectivity in attention deficit hyperactivity disorder. Brain and Behavior, 6(12). DOI: 10.1002/brb3.582

Singh, A., Yeh, C. J., Verma, N., \& Das, A. K. (2015). Overview of attention deficit hyperactivity disorder in young children. Health Psychology Research, 3(2): 2115. DOI: 10.4081/hpr.2015.2115 
Skogli, E. W., Teicher, M. H., Andersen, P. N., Hovik, K. T., \& Øie, M. (2013). ADHD in girls and boys - gender differences in co-existing symptoms and executive function measures. $B M C$ Psychiatry, 13(298). DOI: 10.1186/1471-244X-13-298

Slobodin, O., \& Davidovitch, M. (2019). Gender Differences in Objective and Subjective Measures of ADHD Among Clinic-Referred Children. Frontiers in Human Neuroscience, 13(441). DOI: $10.3389 /$ fnhum.2019.00441

Smith, V., Mitchell, D. J., \& Duncan, J. (2019). The effect of rule retrieval on activity in the default mode network. NeuroImage, 202. DOI: 10.1016/j.neuroimage.2019.116088

Smitha, K. A., Akhil Raja, K., Arun, K. M., Rajesh, P. G., Thomas, B., Kapilamoorthy, T. R., \& Kesavadas, C. (2017, August 1). Resting state fMRI: A review on methods in resting state connectivity analysis and resting state networks. Neuroradiology Journal, 30(4), 305-317. DOI: $10.1177 / 1971400917697342$

Sun, L., Cao, Q., Long, X., Sui, M., Cao, X., Zhu, C., ... Wang, Y. (2012). Abnormal functional connectivity between the anterior cingulate and the default mode network in drug-naïve boys with attention deficit hyperactivity disorder. Psychiatry Research - Neuroimaging, 201(2), 120127. DOI: $10.1016 /$ j.pscychresns.2011.07.001

Sutoko, S., Monden, Y., Tokuda, T., Ikeda, T., Nagashima, M., Funane, T., ... Dan, I. (2020). Atypical Dynamic-Connectivity Recruitment in Attention-Deficit/Hyperactivity Disorder Children: An Insight Into Task-Based Dynamic Connectivity Through fNIRS Study. Frontiers in Human Neuroscience, 14(3). DOI: 10.3389/fnhum.2020.00003 
Tao, J., Jiang, X., Wang, X., Liu, H., Qian, A., Yang, C., ... Wang, M. (2017). Disrupted control-related functional brain networks in drug-naive children with attention-deficit/hyperactivity disorder. Frontiers in Psychiatry, 8(246). DOI: 10.3389/fpsyt.2017.00246

Uddin, L. Q., Kelly, A. M. C., Biswal, B. B., Margulies, D. S., Shehzad, Z., Shaw, D., ... Milham, M. P. (2008). Network homogeneity reveals decreased integrity of default-mode network in ADHD. Journal of Neuroscience Methods, 169(1), 249254. DOI: $10.1016 / j . j n e u m e t h .2007 .11 .031$

Van Oort, J., Tendolkar, I., Hermans, E. J., Mulders, P. C., Beckmann, C. F., Schene, A. H., ... van Eijndhoven, P. F. (2017, December 1). How the brain connects in response to acute stress: A review at the human brain systems level. Neuroscience and Biobehavioral Reviews. DOI: 10.1016/j.neubiorev.2017.10.015

Voeller, K. K. S. (2004). Attention-deficit hyperactivity disorder (ADHD). Journal of Child Neurology, 19(10), 798-814. DOI: 10.1177/08830738040190100901

Wang, X. H., \& Li, L. (2015). Altered temporal features of intrinsic connectivity networks in boys with combined type of attention deficit hyperactivity disorder. European Journal of Radiology, 84(5), 947-954. DOI: 10.1016/j.ejrad.2015.02.018

Washington, S. D., \& VanMeter, J. W. (2015). Anterior-Posterior Connectivity within the Default Mode Network Increases During Maturation. International Journal of Medical and Biological Frontiers, 21(2), 207-218 
Watabe, T., \& Hatazawa, J. (2019). Evaluation of Functional Connectivity in the Brain Using Positron Emission Tomography: A Mini-Review. Frontiers in Neuroscience, 13, 775. DOI: $10.3389 /$ fnins. 2019.00775

Willcutt, E. G. (2012). The Prevalence of DSM-IV Attention-Deficit/Hyperactivity Disorder: A MetaAnalytic Review. Neurotherapeutics, 9(3), 490-499. DOI: 10.1007/s13311-012-0135-8

Wong H.C., Zaman, R. (2019). Neurostimulation in Treating ADHD. Psychiatria Danubina, 31(3), 265275.

Zhang, J., Cheng, W., Liu, Z., Zhang, K., Lei, X., Yao, Y., ... Feng, J. (2016). Neural, electrophysiological and anatomical basis of brain-network variability and its characteristic changes in mental disorders. Brain: A Journal of Neurology, 139(8), 23072321. DOI: $10.1093 /$ brain/aww143

Zhou, Z. W., Fang, Y. T., Lan, X. Q., Sun, L., Cao, Q. J., Wang, Y. F., ... Zhang, H. (2019). Inconsistency in abnormal functional connectivity across datasets of ADHD-200 in children with attention deficit hyperactivity disorder. Frontiers in Psychiatry, 10(692). DOI: 10.3389/fpsyt.2019.00692 


\title{
Appendix A
}

\author{
(Q) \\ THE JOANNA BRIGGS INSTITUTE
}

\section{JBI Critical Appraisal Checklist for Case Control Studies}

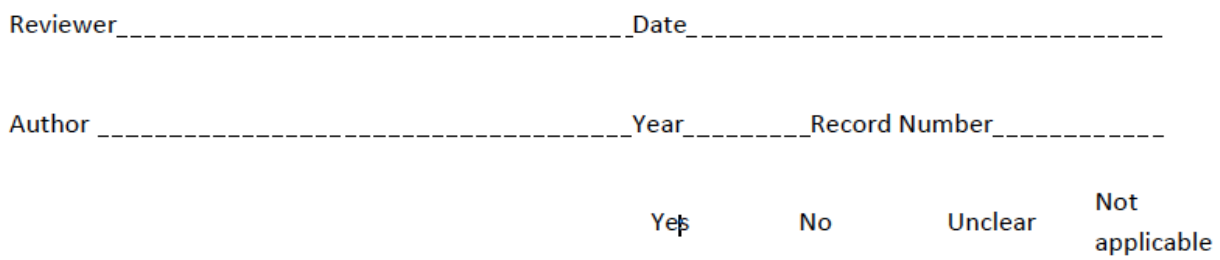

1. Were the groups comparable other than the presence of disease in cases or the absence of disease in controls?

2. Were cases and controls matched appropriately?

3. Were the same criteria used for identification of cases and controls?

4. Was exposure measured in a standard, valid and reliable way?

5. Was exposure measured in the same way for cases and controls?

6. Were confounding factors identified?

7. Were strategies to deal with confounding factors stated?

8. Were outcomes assessed in a standard, valid and reliable way for cases and controls?

9. Was the exposure period of interest long enough to be meaningful?

10. Was appropriate statistical analysis used?

Overall appraisal: $\quad$ Include $\square$ Exclude $\square$ Seek further info

Comments (Including reason for exclusion) 